\title{
Targeting B7-H3 via chimeric antigen receptor T cells and bispecific killer cell engagers augments antitumor response of cytotoxic lymphocytes
}

Jie Liu ${ }^{1,2+}$, Shuo Yang ${ }^{1,2 \dagger}$, Bihui Cao ${ }^{3 \dagger}$, Guangyu Zhou ${ }^{1,2}$, Fengjuan Zhang ${ }^{1,2}$, Yuan Wang ${ }^{1,2}$, Rixin Wang ${ }^{1,2}$, Lipeng Zhu' ${ }^{1,2}$, Ya Meng ${ }^{4}$, Cong Hu ${ }^{4}$, Hui Liang ${ }^{4}$, Xu Lin ${ }^{4}$, Kangshun Zhu ${ }^{3}$, Guokai Chen ${ }^{1,2}$, Kathy Qian Luo ${ }^{1,2}$, Lijun $\mathrm{Di}^{1,2}$ and Qi Zhao ${ }^{1,2^{*}}$ (D)

\begin{abstract}
Background: $\mathrm{B} 7-\mathrm{H} 3$, an immune-checkpoint molecule and a transmembrane protein, is overexpressed in non-small cell lung cancer (NSCLC), making it an attractive therapeutic target. Here, we aimed to systematically evaluate the value of B7-H3 as a target in NSCLC via T cells expressing B7-H3-specific chimeric antigen receptors (CARs) and bispecific killer cell engager (BiKE)-redirected natural killer (NK) cells.

Methods: We generated B7-H3 CAR and B7-H3/CD16 BiKE derived from an anti-B7-H3 antibody omburtamab that has been shown to preferentially bind tumor tissues and has been safely used in humans in early-phase clinical trials. Antitumor efficacy and induced-immune response of CAR and BiKE were evaluated in vitro and in vivo. The effects of $\mathrm{B} 7-\mathrm{H} 3$ on aerobic glycolysis in NSCLC cells were further investigated.

Results: B7-H3 CAR-T cells effectively inhibited NSCLC tumorigenesis in vitro and in vivo. B7-H3 redirection promoted highly specific T-cell infiltration into tumors. Additionally, NK cell activity could be specially triggered by B7-H3/CD16 BiKE through direct CD16 signaling, resulting in significant increase in NK cell activation and target cell death. BiKE improved antitumor efficacy mediated by NK cells in vitro and in vivo, regardless of the cell surface target antigen density on tumor tissues. Furthermore, we found that anti-B7-H3 blockade might alter tumor glucose metabolism via the reactive oxygen species-mediated pathway.
\end{abstract}

Conclusions: Together, our results suggest that B7-H3 may serve as a target for NSCLC therapy and support the further development of two therapeutic agents in the preclinical and clinical studies.

Keywords: B7-H3, Chimeric antigen receptor, Bispecific antibody, Non-small cell lung cancer, PD-L1, BiKE, CART

*Correspondence: qizhao@um.edu.mo; zhaoqi@alumni.cuhk.net ${ }^{\dagger}$ Jie Liu, Shuo Yang and Bihui Cao have contributed equally to this work ${ }^{1}$ Cancer Centre, Faculty of Health Sciences, University of Macau, Taipa, Macau SPR, China

Full list of author information is available at the end of the article

\section{Background}

Lung cancer is the most common type of cancer worldwide and is associated with the highest mortality among all common cancers. Non-small cell lung carcinoma (NSCLC) is a major subtype of epithelial lung cancer and accounts for a majority of cases [1]. Metastatic spread of cancer is the reason for most NSCLC-related deaths [2]. Lung cancer cells frequently metastasize to some major original author(s) and the source, provide a link to the Creative Commons licence, and indicate if changes were made. The images or other third party material in this article are included in the article's Creative Commons licence, unless indicated otherwise in a credit line to the material. If material is not included in the article's Creative Commons licence and your intended use is not permitted by statutory regulation or exceeds the permitted use, you will need to obtain permission directly from the copyright holder. To view a copy of this licence, visit http://creativecommons.org/licenses/by/4.0/. The Creative Commons Public Domain Dedication waiver (http://creativeco mmons.org/publicdomain/zero/1.0/) applies to the data made available in this article, unless otherwise stated in a credit line to the data. 
organs, such as bone, brain, lung and liver [3]. Although most NSCLC patients receive multiple treatments, including surgery, radiation, chemotherapy, targeted therapy, NSCLC still exhibits low cure rate, high recurrence and mortality [4]. Attempts have been made to develop new strategies for the treatment for NSCLC [5]. To date, immunotherapy has shown promise in patients with metastatic NSCLC.

In recent years, immune checkpoint therapy becomes a breakthrough strategy to reactivate antitumor immune responses [6]. Programmed cell death protein 1 (PD1) and its ligand PD-L1 axis, as an inhibitory immune checkpoint signaling pathway, play a crucial role in the progression of tumor. In particular, inhibiting PD-1 and its ligand PD-L1 axis has shown remarkably results in NSCLC treatment. Currently, two antibodies (nivolumab and pembrolizumab) against PD-1 and two (atezolizumab and durvalumab) against PD-L1 have been approved for treating advanced stage NSCLC [7]. However, anti-PD-1/ PD-L1 therapy remains challenging because of the low response rates [8]. Multiple factors, including T-cell infiltration, neoantigen burden and tumor metabolism, are involved in the immune checkpoint blockade [9].

B7-H3, also known as CD276, is a type I transmembrane protein that shares up to $30 \%$ amino acid identity with PD-L1 $[10,11]$. The receptor of the B7-H3 protein remains unclear. $\mathrm{B} 7-\mathrm{H} 3$ contributes to a co-inhibitory immune signal during modulation of cytotoxic lymphocyte function in cancer immunity [12]. While B7-H3 protein is expressed at low levels in most normal tissues, it is aberrantly expressed on differentiated malignant cells and cancer-initiating cells, with limited heterogeneity, and in multiple tumor types, including lung, colon, breast and ovarian cancers [13]. In head and neck squamous cell cancer and pancreatic ductal adenocarcinoma, high $\mathrm{B} 7-\mathrm{H} 3$ expression is observed on cancer-initiating cells. Moreover, it is overexpressed in the tumor vasculature and stroma fibroblasts $[14,15]$. B7-H3 plays an important role in tumor immune evasion and metastasis [16]. In NSCLC patients, B7-H3 overexpression is frequently associated with lower level of tumor-infiltrating lymphocytes [17]. B7-H3 expression may be correlated with EGFR gene expression status and efficacy of antiPD-1 therapy [18]. Recent evidence indicated that B7-H3 expression potentially involves in resistance to anti-PD-1/ PD-L1 blockade in NSCLC and ovarian cancer $[18,19]$. B7-H3 represents an attractive target for antibody-based immunotherapy. However, the molecular mechanisms of B7-H3-modulation of cancer immunity are not clear.

Due to its broad expression across a panel of tumor types, B7-H3 becomes an attractive therapeutic target. Recently, several monoclonal antibodies (mAbs) targeting $\mathrm{B} 7-\mathrm{H} 3$ have generated promising results against pancreatic adenocarcinoma [20], glioblastoma [21, 22], pediatric solid tumors [23, 24], and lymphoma [25]. Specifically, recently developed anti-B7-H3 mAb, 8H9 (omburtamab) and its humanized forms, inhibited the growth of different B7-H3-positive tumor cells through antibody-dependent cell-mediated cytotoxicity (ADCC) or as immunoconjugates in preclinical [26-29]. ${ }^{124}$ I could be safely delivered with $8 \mathrm{H} 9$ by direct injection into human pontine gliomas for both PET imaging and therapy [30], while ${ }^{131}$ I- $8 \mathrm{H} 9$ administered to the cerebrospinal fluid showed potential in improving survival among patients with metastasis to the central nervous system and the leptomeninges [24].

Adoptive immunotherapy that utilizes effector lymphocytes expressing tumor-specific antibodies is a promising approach to treat cancer [31-33]. Genetic modifications using $\mathrm{B} 7-\mathrm{H} 3$ chimeric antigen receptors (CARs) gave promising results in xenografts of pediatric tumors [20, 23], glioblastoma [21] and melenoma [34]. To facilitate immune cell responses, two modalities, CARs and bispecific killer cell engagers (BiKE), use single chain variable fragments (scFvs) to redirect cytotoxic lymphocytes against specific antigens that are expressed on tumor cells [35]. These novel strategies have emerged as potentially curative therapies in the treatment for leukemia and some solid tumors. Here, we aimed to systematically evaluate the value of $\mathrm{B} 7-\mathrm{H} 3$ as a target in NSCLC via T cells expressing B7-H3-specific CARs and BiKE-redirected natural killer (NK) cells.

\section{Methods}

\section{Human tissue samples}

Either formalin-fixed paraffin-embedded or surgical tissue samples were obtained from the Second Affiliated Hospital, Guangzhou Medical University, and Zhuhai People's Hospital, Jinan University. Buffy coat samples collected from healthy adult donors were obtained from Macau Blood Center. All procedures were in accordance with the ethical standards approved by the human ethics committees.

\section{RNA-sequencing analysis}

The B7-H3 mRNA expression in 110 normal lung tissues, 488 lung adenocarcinoma (LUAD) samples and 509 lung squamous cell carcinoma (LUSC) samples with different stages was analyzed using $R$ packages ggplot 2 and ggbeeswarm. Data were downloaded from the Cancer Genome Atlas (TCGA) (http://www.oncolnc.org). 


\section{Cell lines and cell culture conditions}

The HEK293, Daudi, MDA-MB-231, NCI-H23, HCC827, A549, BT-474, OVCAR-3, SK-OV-3 cell lines were obtained from the Stem Cell Bank, Chinese Academy of Sciences. HCC 1954 cell line was obtained from MSKCC. DLD-1, HCT 116 and PANC-1 cell lines were provided by Prof. Hang-Fai Kwok. SF188 and U251 cell lines are provided by Prof Gang Li. OCI-AML-3 and MOLM-13 cell line was provided by Dr. Tong-Kam Leung. These cell lines were cultured in either RPMI-1640, DMEM or DMEM/F12 supplemented with $10 \%$ fetal bovine serum (FBS) (GIBCO), $100 \mathrm{U} / \mathrm{mL}$ penicillin and $100 \mu \mathrm{g} / \mathrm{mL}$ streptomycin (GIBCO) at $37{ }^{\circ} \mathrm{C}$ with $5 \% \mathrm{CO}_{2}$. The FreeStyle 293-F cells were obtained from Invitrogen and cultured in Freestyle 293 expression medium (GIBCO) in the incubator shaker set at $125 \mathrm{rpm}, 8 \% \mathrm{CO}_{2}$, and $37^{\circ} \mathrm{C}$.

\section{Antibodies}

Antibodies for APC-CD3, PE-CD4, PE/Cy7-CD8, Alexa Fluor647-CD56, PE-CD107a, PE-CCR7, PE/Cy7-CD62L, $\mathrm{PE} / \mathrm{Cy} 7$-perforin, PE-granzyme $\mathrm{B}, \mathrm{PE}-\mathrm{PD}-\mathrm{L} 1$ were purchased from BioLegend. Goat anti-B7-H3 antibody (MAB1027) was purchased from R\&D System. Humanized anti-B7-H3 IgG (8H9) was expressed and purified in the laboratory (for details, see Additional file 1). Mouse anti-CD16 antibody (3G8) was purchased from BD Biosciences. PE-conjugated anti-human Fc antibody and HRP anti-human IgG antibody were purchased from Invitrogen. HRP-conjugated rabbit anti-goat IgG antibodies were purchased from Jackson ImmunoResearch. Rabbit antihuman PD-L1 antibody (13,684), HRP-conjugated anti- $\beta$-actin and anti-GAPDH antibodies were purchased from Cell Signaling.

\section{Generation of B7-H3-specific CAR-T cells}

The DNA sequence of the single chain variable fragment $(\mathrm{scFv})$ of $8 \mathrm{H} 9$ antibody was synthesized and then introduced into the pLVX lentivirus backbone plasmid, containing E1 $\alpha$ promoter, a CD8 leader sequence, CD8- $\alpha$ transmembrane domain, a $4-1 \mathrm{BB}$ and a $\mathrm{CD} 3 \zeta$ intracellular signaling domains. Lentiviruses carrying the B7-H3-CAR were produced in HEK293 cells that were co-transfected with B7-H3-CAR lentiviral vector and packaging plasmids (PsPAX2 and pMD2.0G) as previously described [36]. The lentiviral supernatants were collected at $72 \mathrm{~h}$ after the transfection and filtrated through a $0.45 \mu \mathrm{m}$ filter (Millipore), followed by centrifugation for $2 \mathrm{~h}$ at 28,000 rpm. For titer calculation, HEK293T cells $\left(5 \times 10^{5}\right.$ per well) were seeded into 12 -well plate and cultured to reach $80 \%$ confluence. The different dilutions of lentiviruses were mixed with polybrene at $5 \mu \mathrm{g} / \mathrm{ml}$ in $1 \mathrm{ml}$ fresh medium. The culture medium in the wells was replaced by the mixture of lentiviruses and incubated for 2 days. After harvesting, the infection percentages of HEK293T cells were counted based on Zsgreeen detection by the flow cytometer. The positive ratio of each well was recorded. The titer can be calculated from cell counting using the following formula:

$$
\text { titer }(\mathrm{TU} / \mathrm{ml})=\frac{\text { Total cell number } \times \text { positive rate }}{\text { added volume of virus }(\mu l)} \times 1000 .
$$

Human peripheral blood mononuclear cells (PBMCs) were isolated from buffy coats using Ficoll reagents (GE Healthcare) and cultured in complete RPMI-1640 supplemented with $2 \mathrm{mM}$ L-glutamine, $100 \mathrm{U} / \mathrm{mL}$ penicillin, $100 \mu \mathrm{g} / \mathrm{mL}$ streptomycin, 10\% FBS and 100U/mL r-human IL-2 (rhIL-2) (CellGenix). PBMCs were stimulated by Dynabeads Human T-Activator CD3/CD28 (Gibco) at a 1:1 $\mathrm{T}$ cell: bead ratio in the growth medium supplemented with rhIL-2. One day after activation, the activated $\mathrm{T}$ cells were transduced with the lentivirus at a multiplicity of infection (MOI) of 5. Spin infection was performed with polybrene at $570 \times \mathrm{g}$ for $1 \mathrm{~h}$ at $32{ }^{\circ} \mathrm{C}$, followed by incubation for 2 days. The anti-CD3/CD28 beads were magnetically removed on day 7 . $T$ cells were expanded in complete RPMI-1640 until used in vitro or in vivo assays. Cells were fed every 2 days and used within 20 days of expansion in all experiments. Vehicle control $\mathrm{T}$ cells were produced in the same conditions.

\section{Production of the B7-H3/CD16 BiKE}

The scFv of the humanized anti-B7-H3 antibody $8 \mathrm{H} 9$ and the $\mathrm{scFv}$ of anti-CD16 antibody 3G8 were generated by coupling of heavy chain variable region (VH) and light chain variable region (VL) via the (GGGGS)3 linker, respectively. The scFvs were cloned into $\mathrm{pComb3x}$ vector. To generate a BiKE targeting B7-H3 and CD16, the antiB7-H3 scFv 8H9 and anti-CD16 scFv 3 G8 were linked with an additional (GGGGS)3 linker and then cloned into the pSecTag B expression vector. Freestyle 293-F cells were used to express bispecific antibodies. Transfection into HEK293 cells was performed as described previously [37]. The soluble $\mathrm{scFv}$ was expressed and purified as previously described [26]. The anti-B7-H3 x CD16 bsAb, anti-B7-H3 scFv and anti-CD16 scFv were purified using Ni-NTA agarose beads (Qiagen).

\section{Cytotoxicity assays}

Cytotoxicity of CAR-T cells was measured using the Calcein-AM release method as previously described with modifications [38]. Targeted cells at $1 \times 10^{6}$ cells $/ \mathrm{mL}$ were incubated with $10 \mu \mathrm{M}$ of Calcein-AM for $30 \mathrm{~min}$ at $37^{\circ} \mathrm{C}$. For CAR-T cells, targeted cells seeded at $1 \times 10^{4}$ cells/ well in the 96-well plate were co-incubated with effector 
CAR-T cells at different effector-to-target (E:T) ratios from $5: 1$ to $40: 1$ in a total volume of $200 \mu \mathrm{L}$ for $4 \mathrm{~h}$.

ADCC assay was performed using PBMC as effectors as previously described with modifications [39]. Targeted cells were labeled with Calcein-AM. Different concentrations of antibodies were incubated with the mixture of tumor cells and PBMC at a 10:1 E:T ratio in a total volume of $200 \mu \mathrm{L}$ for $4 \mathrm{~h}$. The spontaneous release control wells and maximum release target control wells were set up in all experiments. Mean fluorescence intensity (MFI) was measured using PerkinElmer Multimode Reader at $495 / 515 \mathrm{~nm}$. The specific lysis ratios were calculated according to the formula:

$$
\text { lysis ratio }(\%)=\frac{\text { MFI }(\text { sample lysis })-\text { MFI }(\text { spontaneous release })}{\text { MFI }(\text { maximum lysis })-\text { MFI }(\text { spontaneous release })} \times 100 \% \text {. }
$$

\section{Xenografted mouse models}

All animal studies were conducted using protocols approved by the Animal Ethics Committees, University of Macau. Six- to eight-week-old female NOD/SCID mice were bred in the Animal Facility at Faculty of Health Sciences. Six- to eight-week-old female NOD/SCID mice were randomly divided into groups ( $n=5$ per group). Each mouse was subcutaneously inoculated with 100 $\mu \mathrm{L}$ PBS containing $1.5 \times 10^{6}$ tumor cells. To investigate the therapeutic effect of B7-H3-specific CAR-T cells, 5 days after tumor inoculation, mice in each group were intravenously treated with PBS, PBS containing $1 \times 10^{7}$ CAR-T cells or vehicle $\mathrm{T}$ cells per mouse on day 0 and day 7 , respectively. To investigate the therapeutic effect of anti-B7-H3 × CD16 BiKE, antibodies (BiKE, B7-H3 scFv, CD16 scFv, $100 \mu \mathrm{g}$ per mouse) were administered intravenously twice a week for a total of four doses. In animals that also received human effector cells with or without antibodies, PBMCs from healthy donors were injected intravenously into mice $\left(1 \times 10^{7}\right.$ cells per mouse). Tumor growth was measured using digital calipers twice a week, and tumor volumes were calculated using the formula $V=1 / 2\left(\right.$ length $\times$ width $\left.^{2}\right)$.

\section{Flow cytometry}

Human B7-H3 expression on cell surface of tumor cells was detected using anti-B7-H3 IgG 8H9, followed by a fluorescently-labeled anti-human Fc antibody. For cytokine measurement of CAR-T cells, target cells (A549 and HCT 116) were seeded at $1 \times 10^{5}$ cells/well in a 96-well plate and co-incubated with effector B7-H3-CAR $\mathrm{T}$ cells at an E:T ratio of 10:1 for $6 \mathrm{~h}$ or $24 \mathrm{~h}$. Cytokine (IFN- $\gamma$, IL-2, IL-4, IL-6, IL-10 and TNF- $\alpha$ ) secretion in the culture supernatants was measured using $\mathrm{BD}^{\mathrm{TM}}$ Cytometric Bead Array Human Th1/Th2 Cytokine Kit II (BD
Biosciences) following the manufacture's instruction. To determine $\mathrm{T}$ cell differentiation, CAR-T cells were co-incubated with tumor cells (A549 and HCT 116) in a E:T of $10: 1$ for $6-24 \mathrm{~h}$, followed by antibody staining for CD3, CD4, CD8, CD107a, CCR7, CD62L, and apoptosis dyes (7-AAD and Annexin V). For measurement for intracellular perforin and granzyme $B, T$ cells were fixed and permeabilized, followed by stained with an anti-perforin antibody and an anti-granzyme B antibody, respectively. All samples were analyzed using the CytoFLEX S (Beckman Coulter) or Accuri ${ }^{\text {TM }}$ C6 (BD Biosciences) flow cytometry. Data were processed using FlowJo software.

\section{Dynamic apoptotic detection by FRET}

A fluorescence resonance energy transfer (FRET)-based measurement of caspase- 3 was used to determine the real-time apoptosis in tumor cells [40]. Briefly, A549 cells carrying caspase-3 biosensor (A549-C3) were seeded $1 \times 10^{5}$ cells/well in the 24-well plate and incubated at $37{ }^{\circ} \mathrm{C}, 5 \% \mathrm{CO}_{2}$ to grow until confluence. After 1 day, $1 \times 10^{6}$ PBMCs with or without $5 \mu \mathrm{g} / \mathrm{mL} \mathrm{BiKE}$ were added to the plate. Then, cells were incubated for different periods to observe the time-dependent FRET changes. The fluorescent images of living cells were acquired using a fluorescence microscope (Zeiss Axio Observer 7) with an excitation at $436 \pm 10 \mathrm{~nm}$, and the emission for YFP detection at $535 \pm 12.5 \mathrm{~nm}$ and CFP at $480 \pm 15 \mathrm{~nm}$. Imaging data were analyzed using ZEN software (Zeiss).

\section{Immunohistochemistry}

For immunohistochemistry (IHC), the samples were fixed with $10 \%$ formalin and processed for paraffin embedding. Sectioned slices were deparaffinized in xylene and rehydrated in graded alcohol, and placed in Tris-buffered saline (TBS) for $15 \mathrm{~min}$. After the antigen retrieval and inactivation of endogenous peroxidase, sections were blocked with animal nonimmune serum (Maxvision) and incubated with goat anti-human B7-H3 primary antibodies MAB1027 and 8H9 overnight at $4{ }^{\circ} \mathrm{C}$, respectively. After the incubation with corresponding secondary antibodies (Maxvision) for $15 \mathrm{~min}$, the sections were stained using the detection kit (Maxvision). Cell nuclei were stained with hematoxylin (Sigma). Finally, sections were dehydrated with absolute ethanol. The pictures of samples were captured in the Olympus TH4-200 microscope. 


\section{ECAR and OCR measurements}

XF96 glycolysis stress test and mito stress test were performed using Seahorse XFe96 Extracellular Flux Analyzer (Agilent) to measure the extracellular acidification rate (ECAR) and oxygen consumption rate (OCR). One day prior to the assay, A549 cells were seeded 7000 cells/ well in a 96-well Seahorse plate. A549 cells were treated with $100 \mathrm{nmol} / \mathrm{L}$ anti-B7-H3 antibody $8 \mathrm{H} 9$ or control antibody for $24 \mathrm{~h}$. Before measurements, the growth medium was replaced with $\mathrm{XF}$ assay medium and the cells were incubated in a $\mathrm{CO}_{2}$-free incubator for $1 \mathrm{~h}$. After the tests, cells were lysed with lysis buffer $(0.1 \%$ triton, $10 \mathrm{mM}$ Tris- $\mathrm{HCl}$ ) and Bradford reagent was utilized to determine the total amount of protein in each well. Final concentrations of reagents utilized in the glycolysis stress were as follows: $10 \mathrm{mmol} / \mathrm{L}$ glucose, $2 \mu \mathrm{mol} / \mathrm{L}$ of oligomycin, and $50 \mathrm{mmol} / \mathrm{L}$ of 2-deoxy-D-glucose (2-DG) in each group. Final concentrations of reagents utilized in the mito stress test were as follows: $2 \mu \mathrm{mol} / \mathrm{L}$ of oligomycin, $2 \mu \mathrm{mol} / \mathrm{L}$ of FCCP, and $0.5 \mu \mathrm{mol} / \mathrm{L}$ of antimycin $\mathrm{A} /$ rotenone in each group.

\section{Intracellular ROS determination}

Intracellular reactive oxygen species (ROS) was measured using 2,7-dichlorofluorescin diacetate as a probe. A549 cells were harvested and incubated with BiKE and control antibodies for $24 \mathrm{~h}$. Then, cells were placed in growth medium, loaded with the probe for $15 \mathrm{~min}$ and then washed once with PBS. Fluorescence intensity was measured using the Accuri ${ }^{\text {TM }}$ C6 flow cytometry.

\section{Statistical analysis}

All statistical analyses were performed using GraphPad Prism software. Data are represented as mean \pm standard deviation or individual values. Significant differences were calculated using the two-way ANOVA, Student's t tests, nonparametric Mann-Whitney test, or log-rank test. $\mathrm{P}$ values are represented as: $" p<0.05, " * p<0.01$, $* * p<0.001$ and ${ }^{* * * * *} p<0.0001$.

\section{Results}

\section{Broad expression of B7-H3 on different tumor cells}

\section{and tissues}

We first examined the expression of $\mathrm{B} 7-\mathrm{H} 3$ in a panel of tumor cell lines, including lung (A549, HCC827 and NCI-H23), breast (MDA-MA-231, BT-474 and HCC1954), colon (DLD-1 and HCT 116), ovarian (OVCAR-3 and SK-OV-3), acute myeloid leukemia (AML) (OCI-AML-3 and MOLM-13), pancreatic cancer (PANC-1), glioblastoma (SF188 and U251) and Burkitt's lymphoma (Daudi) cell lines, using flow cytometry and western blot assays. As shown in Additional file 1:
Fig. S1A, immunofluorescent staining showed that B7-H3 was strongly expressed in tumor cell lines (A549, HCC827, HCT-116, DLD1, MDA-MB-231, OCI-AML-3, BT-474, OVCAR-3, SK-OV-3, PANC-1, HCC1954, SF188 and U251), while NCI-H23 and MOLM-13 cells were weakly stained. In contrast, B7-H3 expression was not detectable in Daudi cells that were used as the negative control, which is consistent with the previous study [41]. We observed that PD-L1 was highly expressed on the surface of B7-H3 + tumor cell lines, including NSCLC (A549), breast cancer (HCC1954), pancreatic cancer (PANC-1), glioblastoma (SF188 and U251) (Additional file 1: Fig. S2). Likewise, Western blot analysis results corroborated that majority of tumor cell lines were found to have a high level of B7-H3 expression, while NCI-H23 and MOLM-13 cells showed the relatively low level. (Additional file 1: Fig. S1B). B7-H3 was still undetectable in Daudi cells. The total amount of B7-H3 expressed in tumor cells was consistent with the results obtained in the cell surface analysis.

To assess the expression levels of $\mathrm{B} 7-\mathrm{H} 3$ in human primary tissues, we next performed IHC staining on the different types of Formalin-fixed paraffin-embedded (FFPE) human tumor (lung cancer, colon cancer, hepatocellular carcinoma, pancreatic cancer, kidney cancer, melanoma) and normal tissues (lung, colon, liver, pancreas, kidney) with the anti-B7-H3 antibody $8 \mathrm{H} 9$ and a goat antihuman B7-H3 antibody from R\&D Systems. IHC staining results showed that B7-H3 was widely expressed in all types of solid tumors with a high percentage $(29 / 39,74 \%)$ but was not detectable in most of the normal tissues (31/34, 91\%). Two normal pancreatic and one kidney tissues showed the weak expression of B7-H3. Of 24 lung cancer

Table 1 IHC staining of human normal and tumor tissues

\begin{tabular}{llllll}
\hline Tissue & Number & Negative (\%) & \multicolumn{2}{l}{ Positive (\%) } \\
\cline { 4 - 6 } & & & ++++ & +++ \\
\hline Tumor & & & & & \\
NSCLC & 21 & 24 & 38 & 19 & 19 \\
Colorectal & 6 & 33 & 33 & 17 & 17 \\
Liver & 4 & 75 & 25 & 0 & 0 \\
Melanoma & 4 & 0 & 0 & 25 & 75 \\
Pancreas & 2 & 0 & 0 & 50 & 50 \\
Renal & 2 & 0 & 100 & 0 & 0 \\
Normal & & & & & 0 \\
Lung & 10 & 100 & 0 & 0 & 0 \\
Colon & 8 & 100 & 0 & 0 & 0 \\
Liver & 4 & 100 & 0 & 0 & 0 \\
Pancreas & 10 & 80 & 20 & 0 & 0 \\
Kidney & 2 & 50 & 50 & 0 & 0 \\
\hline
\end{tabular}


samples, $76 \%$ were positive for B7-H3, with $38 \%$ demonstrating high-intensity staining of $2+$ and $3+$. No positive staining was noted in normal lung tissues. The details of the IHC results are provided in Table 1. Representative specimens are shown in Fig. 1a. Although 8H9 did not perform adequately when used as a primary antibody to stain FFPE tumor sections, the staining of $8 \mathrm{H} 9$ was specific for tumor tissues but not normal tissues. After being

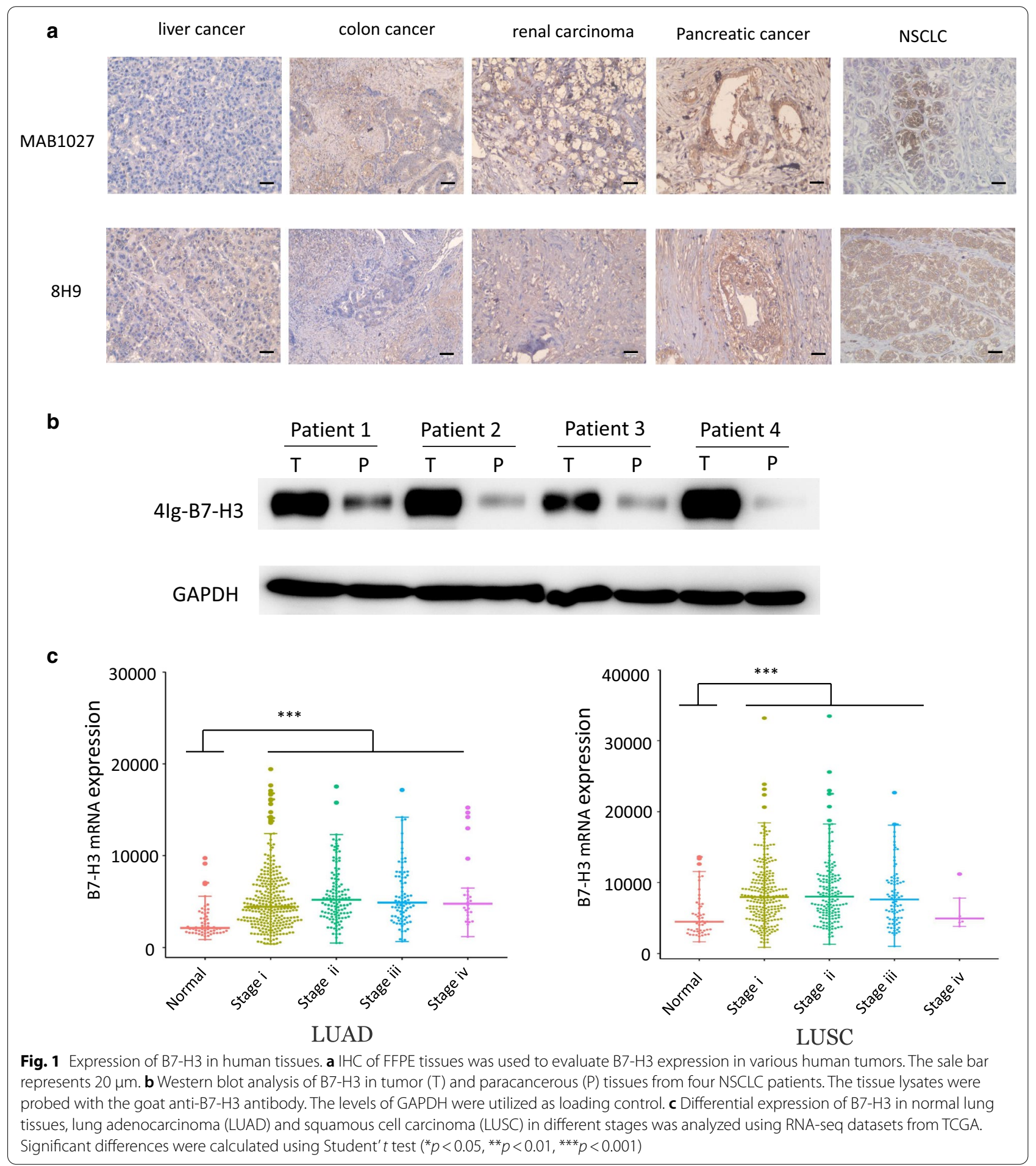


(See figure on next page.)

Fig. 2 Generation of B7-H3 CAR-T cells and their in vitro antitumor activity. a Schematic diagram of the CAR construct. CAR gene was cloned into a lentiviral vector, which contained an internal ribosome entry site (IRES)-green fluorescence protein (ZsGreen) sequence. The resulting CAR was composed of the leader sequence (LS), a scFv, a hinge (H) region, a CD8a transmembrane domain (TM), along with the 4-1BB domain and the CD3Z chain. b Subsets of B7-H3 CAR-T cells were derived from a single healthy donor. T cells were stained with anti-CD3, anti-CD4, or anti-CD8 antibodies and then analyzed using flow cytometry. $\mathbf{c}$ Proliferation of B7-H3 CAR-T cells and vehicle T cells activated by anti-CD3/CD28 beads. $\mathbf{d}$ Cytotoxicity of B7-H3 CAR-T cells (red line) and vehicle T cells (blue line) cells against various tumor cell lines. e Apoptosis in target A549 cells induced by B7-H3 CAR-T cells and vehicle T cells as control at different E:T ratios. Representative graphs are shown. The $p$ values of the difference between the CAR group and the control group were analyzed using ANOVA

stained with an antihuman PD-L1 antibody, approximately $30 \%$ of B7-H3 + lung tumor samples showed positive (Additional file 1: Fig. S3). One pancreatic sample and one melanoma tumor sample showed positive for PD-L1. Moreover, the fresh tumor and paracancerous tissues were collected from four NSLCL patients and analyzed for B7-H3 expression using Western blot. It is noteworthy that in both tumor and surrounding tissues, B7-H3 showed high level of expression (Fig. 1b). We further evaluated the mRNA expression of $\mathrm{B} 7-\mathrm{H} 3$ in the patients with LUAD or LUSC with different stages using data from TCGA (Fig. 1c). We found that the mRNA levels of B7-H3 in LUAD $(p<0.001)$ and LUSC $(p<0.001)$ were significantly higher than those in the normal lung tissues. High B7-H3 expression was significantly associated with poor 5-year overall survival (5yr-OS) of patients with LUAD $(p=0.0037$; Additional file 1: Fig. S4). Its high expression level had no significant effect on OS of patients with LUSC. Taken together, these experiments demonstrated that $\mathrm{B} 7-\mathrm{H} 3$ expression patterns were highly conserved in lung cancer.

\section{B7-H3 CAR was effective to slow down NSCLC growth}

The B7-H3 CAR was generated by linking the scFv of anti-B7-H3 antibody $8 \mathrm{H} 9$ to the $\mathrm{CD} 8$ transmembrane domain, the intracellular 4-1BB co-stimulation with the CD3 $\zeta$ signaling domain (Fig. 2a). The expression of the B7-H3 CAR on $\mathrm{T}$ cells was determined by detection of the co-expressed ZsGreen. Transduction efficiencies for the B7-H3 CAR and vehicle ranged from 60 to $75 \%$ in $293 \mathrm{~T}$ cells (Additional file 1: Fig. S5A) and human T cells (Additional file 1: Fig. S5B), respectively. After lentiviral transduction, the transduction efficacy of $\mathrm{T}$ cells ranged from $60-70 \%$ by detection of the report gene. The expanded cells showed high viability (above 95\%). Compared with vehicle $\mathrm{T}$ cells, B7-H3 CAR-T cells showed no significant differences in neither $\mathrm{CD} 4 / \mathrm{CD} 8$ ratios (Fig. 2b) nor proliferation (Fig. 2c). The results of quantitative PCR (qPCR) showed that the B7-H3 CAR was specifically expressed in human T cells (Additional file 1: Fig. S5C).

The in vitro cytotoxicity of B7-H3 CAR T cells was evaluated against six B7-H3-positive tumor cell lines
(A549, HCT 116, OVCAR-3, SK-OV-3, DLD-1 and BT-474). The tumor cells were cocultured with B7-H3 CAR-T cells or vehicle $\mathrm{T}$ cells at a different effector/target (E: T) cell ratios. As shown in Fig. 2d, B7-H3 CAR T cells conferred antitumor lytic activity. All of B7-H3-positive tumor cell lines efficiently responded to the B7-H3 CAR. There was no obvious cytotoxicity of vehicle $T$ cells at all E:T ratios. We have further analyzed apoptosis in A549 and HCT 116 cells induced by B7-H3 CAR-T cells. The percentage of tumor cells that underwent apoptosis was significantly higher in the presence of B7-H3 CAR-T cells than vehicle $\mathrm{T}$ cells (Fig. 2e).

The in vivo antitumor efficacy of B7-H3 CAR T cells was evaluated using xenograft mouse models of NSCLC (A549) and colorectal cancer (HCT 116). Subcutaneous xenotransplanted tumor models were established in NOD/SCID mice. The mice were administered with two infusions of B7-H3 CAR or vehicle T cells intravenously (i.v.) via tail vein on day 0 and day 7 , respectively (Fig. 3a). In xenograft models of A549 (Fig. 3b, d) and HCT 116 (Fig. 3c, e), B7-H3 CAR-T cells successfully delayed tumor growth and prolonged survival in animals compared with vehicle $T$ cells. No significant weight loss was observed in mice (Additional file 1: Fig. S6A-B). No treatment-related adverse effects were observed in all groups treated with B7-H3 CAR-T cells. H\&E staining showed that no evident lesions were formed in major organs collected from mice that were treated with $\mathrm{B} 7-\mathrm{H} 3$ CAR-T compared with the control group (Fig. 3f). The results suggested that $\mathrm{B} 7-\mathrm{H} 3 \mathrm{CAR}-\mathrm{T}$ cells had no obvious systemic acute toxicity in major organs that were harvested from A549-injected mice. Overall, the B7-H3 CAR was effective to delay tumor growth in tumor-bearing mice without causing detectable organ toxicity.

\section{B7-H3 redirection enhanced $\mathrm{T}$ cell functional properties and tumor infiltration}

We assessed key cytokine secretion of B7-H3 CAR-T cells in vitro. After 24-h co-incubation of tumor cells and effector T cells at an E:T ratio of 10:1, B7-H3 CAR-T cells produced significantly higher amounts of IFN- $\gamma$, TNF- $\alpha$, IL-2, IL-6, IL-4 and IL-10 in the culture supernatants compared with vehicle T cells (Fig. 4a). To further 
a

\begin{tabular}{|c|c|c|c|c|c|c|c|c|c|}
\hline 5'LTR & $\psi$ & LS & $8 \mathrm{H} 9 \mathrm{scFv}$ & $\begin{array}{c}\text { CD8 H } \\
\text { \& TM }\end{array}$ & $4-1 \mathrm{BB}$ & CD3ろ & $\begin{array}{c}\text { IRE } \\
\text { S }\end{array}$ & ZsGreen1 & 3'LTR \\
\hline
\end{tabular}

b
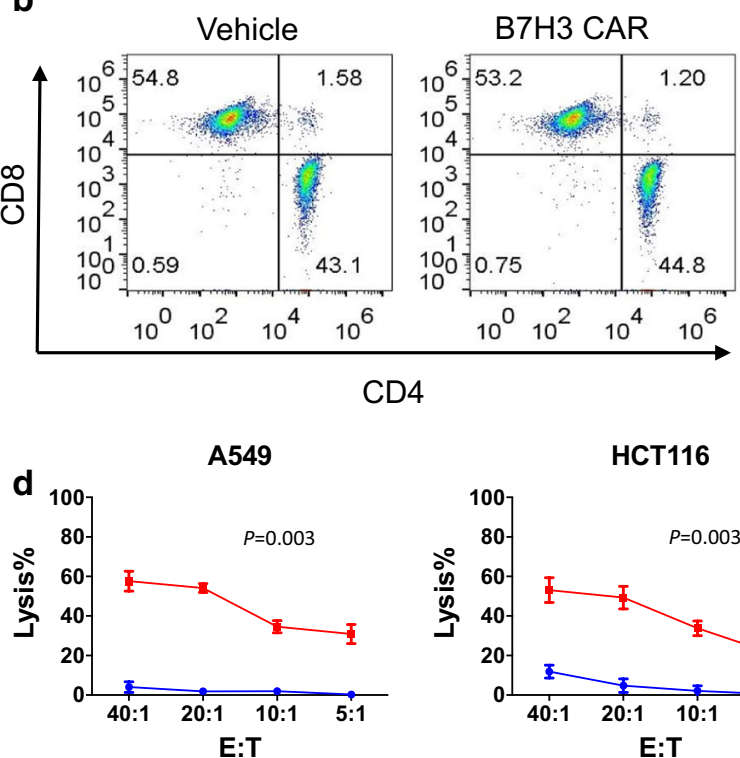

SKOV3

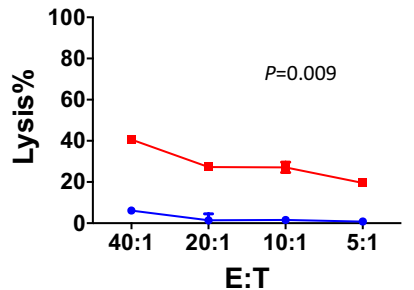

e

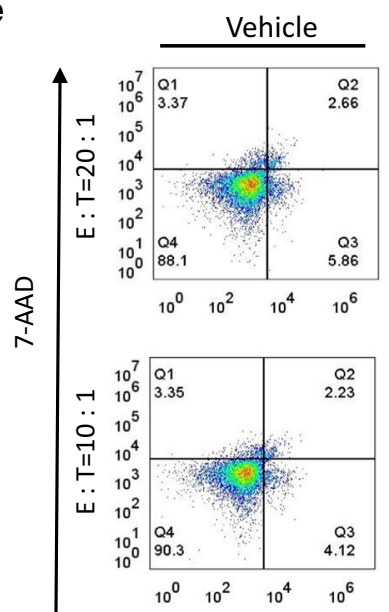

HCT116

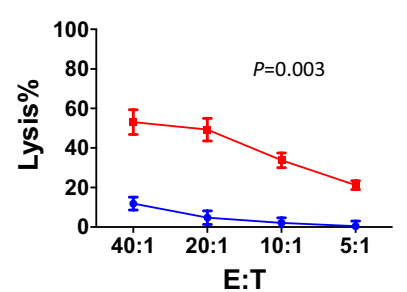

DLD1

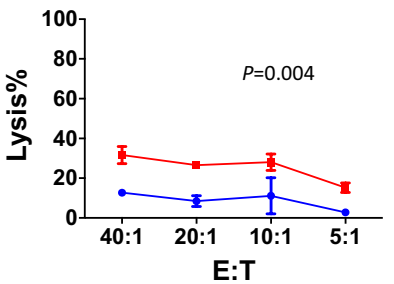

B7-H3 CAR
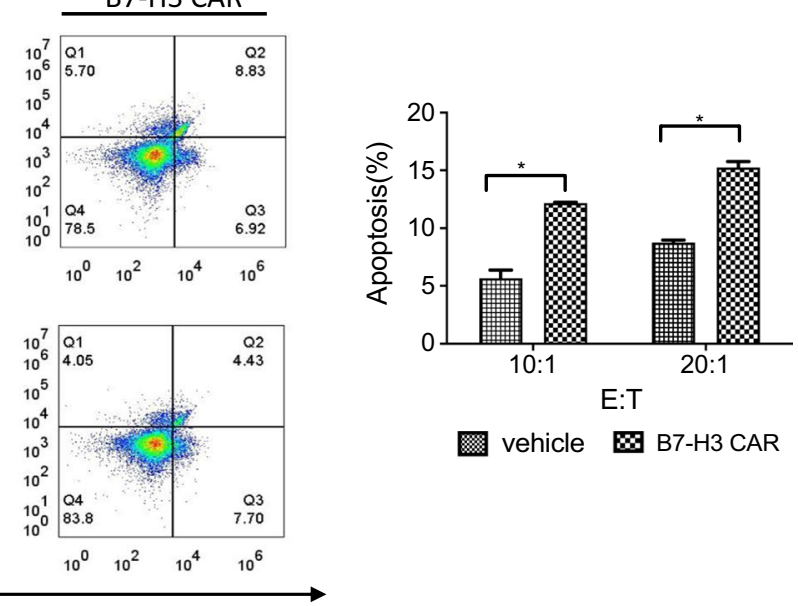

圆 vehicle $\mathbf{\otimes}$ B7-H3 CAR

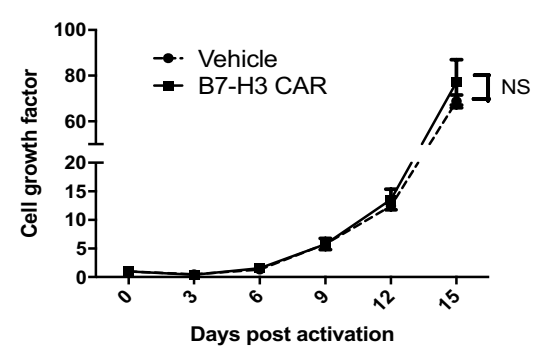

OVCAR3

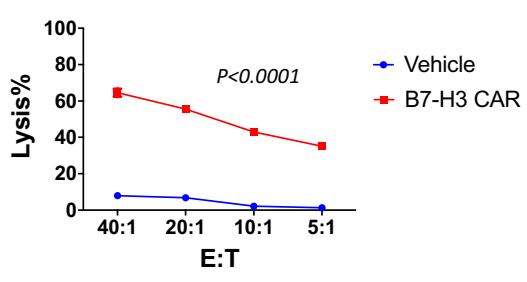

BT474

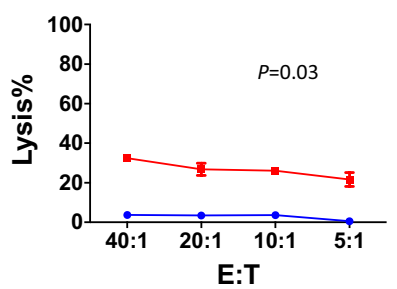




\section{(See figure on next page.)}

Fig. 3 Therapeutic effects of B7-H3 CAR-T cells in tumor xenografts. a Treatment scheme of B7-H3 CAR-T cells in A549 or HCT 116 xenograft models. b-e Tumor growth in A549-injected mice b or HCT 116-injected mice $\mathbf{c}$ was measured using digital caliper, and tumor area was calculated ( $n=5$ ). Mean values per treatment group are shown. The $p$ values of treatment were analyzed using ANOVA. Survival curves of A549-injected mice $\mathbf{d}$ or HCT 116-injected mice e are shown. The $p$ values of survival curves were analyzed using the log-rank (Mantel-Cox) test. Data are presented as the mean \pm standard deviation. ${ }^{*} p<0.05,{ }^{* *} p<0.01,{ }^{* * *} p<0.001$. $\mathbf{f}$ H\&E staining of major organs in mice treated with CAR-T cells. $\mathbf{g}$ Tumor infiltration of B7-H3 CAR-T cells in A549-injected mice. On days 1 and 2, the tumors were harvested, sliced, fixed and imaged in the fluorescence microscope. Representative images are shown. ZsGreen is used as the reporter of CAR-T cells. Representative images are shown

determine CAR-T cell phenotype, we examined the functional status of $\mathrm{CD} 8^{+} \mathrm{T}$ cells that were in contact with target cells. B7-H3 CAR-T cells exhibited the increased proportion of CCR7 $7^{+} \mathrm{CD} 62 \mathrm{~L}^{+}$cells compared with vehicle control $\mathrm{T}$ cells, suggesting that B7-H3 CAR-T cells differentiated into the naïve and central memory $\mathrm{T}$ cells which are considered as favorable phenotypic characteristics to ensure persistence and antitumor effects (Fig. 4b). Three degranulation markers, namely CD107a, granzyme $B$ and perforin, were detected on cell surface of B7-H3 CAR-T cells. As shown in Fig. 4c, there was a significantly increased level of CD107a expression in B7-H3 CAR-T cells compared with that in control $\mathrm{T}$ cells. We further demonstrated that intracellular granzyme $B$ and perforin levels in B7-H3 CAR $\mathrm{T}$ cells were higher than those in vehicle $\mathrm{T}$ cells by flow cytometry (Fig. 4c). The results of $\mathrm{qPCR}$ further verified that the total mRNA level of granzyme B was significantly increased in B7-H3 CAR T cells (Additional file 1: Fig. S7). Therefore, B7-H3 CAR-T cells possibly exert cytotoxic antitumor effects through a degranulation-mediated mechanism.

To further analyze the in vivo mechanism of $\mathrm{B} 7-\mathrm{H} 3$ CAR action, we performed fluorescent imaging analysis on tumors and organs excised from the mice that were undergoing treatment. Mice were killed at 1-2-day postinjection of B7-H3 CAR-T and vehicle T cells. Tumors and major organs were excised, fixed, sliced and subjected to fluorescence microscopy observation. In contrast to the control group, the B7-H3 CAR-treated tumor samples exhibited $\mathrm{T}$ cell infiltration throughout the tissue at 2-day after treatment (Fig. 3g). Other major organs, such as the heart, spleen, lung, liver and kidney, did not display obvious cross-reactivity with CAR-T cell (Additional file 1: Fig. S8). These data corroborate that B7-H3 redirection promotes $\mathrm{T}$ cell to infiltrate into tumors in a specific manner.

\section{B7-H3/CD16 BiKE induced antitumor efficacy mediated by NK cells}

The B7-H3/CD16 BiKE, which simultaneously targets B7-H3 and a NK cell activator CD16, was constructed by linking the anti-B7-H3 $8 \mathrm{H} 9 \mathrm{scFv}$ and the anti-CD16 $\mathrm{scFv}$ with a nonimmunogenic (glycine ${ }_{4}-$ serine) $_{3}$ linker (Fig. 5a). A C-terminal $6 \times$ His-tag was added for purification of the protein products. The BiKE was expressed in Freestyle 293-F cells and purified using nickel-NTA resins. Meanwhile, the anti-B7-H3 scFv and anti-CD16 scFv antibodies were produced and purified. The molecular weight and purity of the BiKE protein and scFvs were shown using SDS-PAGE (Additional file 1: Fig. S9B) and SEC (Fig. 5b). The purified B7-H3/ CD16 BiKE exhibited the binding ability to both soluble 4Ig-B7-H3 and CD16a proteins in ELISA assay (Additional file 1: Fig. S9C-D). BiKE showed comparable binding affinity to 4Ig-B7-H3 protein compared with the $8 \mathrm{H} 9 \mathrm{scFv}$ as previously reported $\left(\mathrm{scFv}, \mathrm{K}_{\mathrm{D}}=6.71 \mathrm{nM}\right.$ vs. BiKE, $K_{D}=2.94 \mathrm{nM}$, Additional file 1: Table S1). Flow cytometry analysis further demonstrated that BiKE recognized CD16 expressed on the cell surface of NK-92MI cells (Additional file 1: Fig. S9E). In a transwell migration assay, CD16a-expressing NK-92 cells and B7-H3-positive A549 cells were seeded at upper and lower champers, respectively. NK cell migration was significantly enhanced after the treatment with B7-H3/CD16 BiKE (Additional file 1: Fig. S10).

To determine the antitumor potency of the BiKE, ADCC assay was performed by co-incubating the effector PBMCs with the solid tumor cell lines (A549, HCC827, NCI-H23, HCT 116), AML cell lines (OCIAML-3) and negative control cell lines (Daudi) at the presence of antibodies with different concentrations. B7-H3/CD16 BiKE-mediated cytotoxicity was specific as the BiKE significantly potentiated cytotoxic activity against B7-H3-positive solid tumor cells, whereas no cell death was observed in a B7-H3-negative cell line Daudi (Fig. 5c). Although NCI-H23 weakly expressed B7-H3, it still displayed the cytotoxicity response to BiKE. Meanwhile, specific lysis was also observed in AML, OCI-AML-3. As controls, the anti-B7-H3 and anti-CD16 scFv had no significant effects on the increase of cell lysis function. Although anti-B7-H3 8 H9 IgG showed the ability to induced ADCC activity [26], we found that BiKE exerted greater ADCC ability than anti-B7-H3 8H9 IgG (Fig. 5d), suggesting that the BiKE may be more efficient at recruiting effector NK cells for targeting cell lysis. Therefore, the addition of B7-H3/CD16 BiKE to the cell culture resulted in significant NK cell cytolytic activity. 

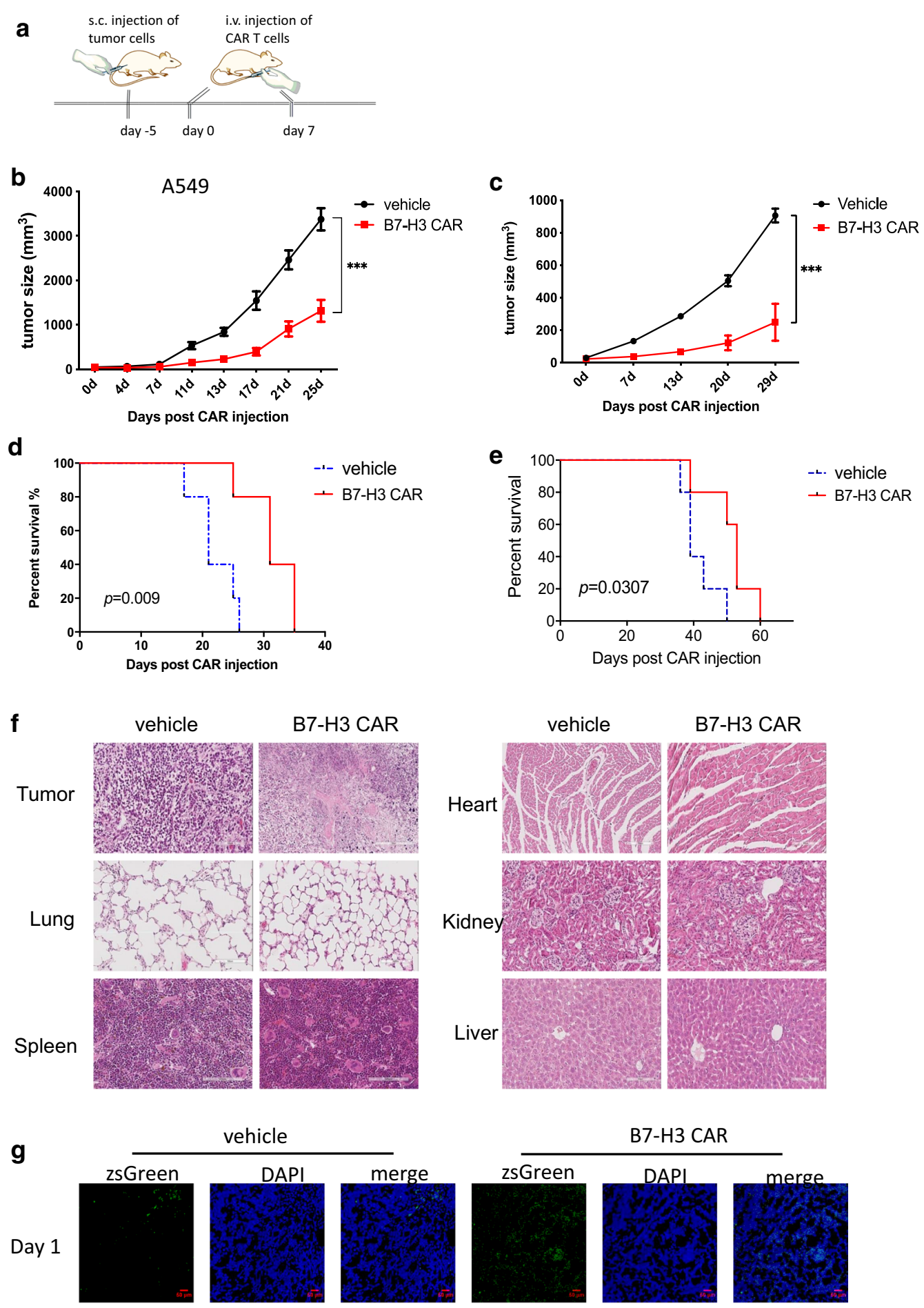

vehicle

B7-H3 CAR
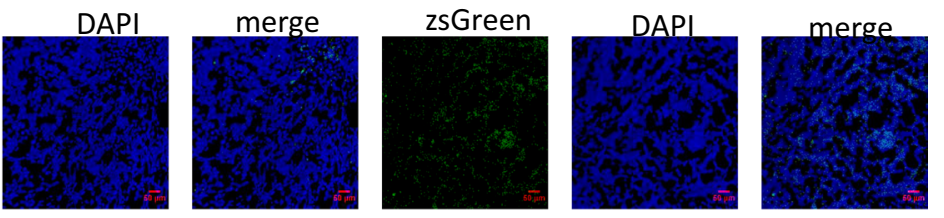

Day 2
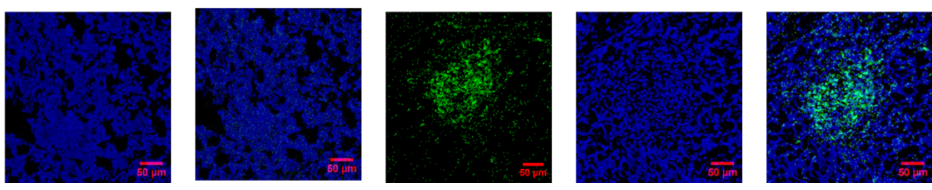


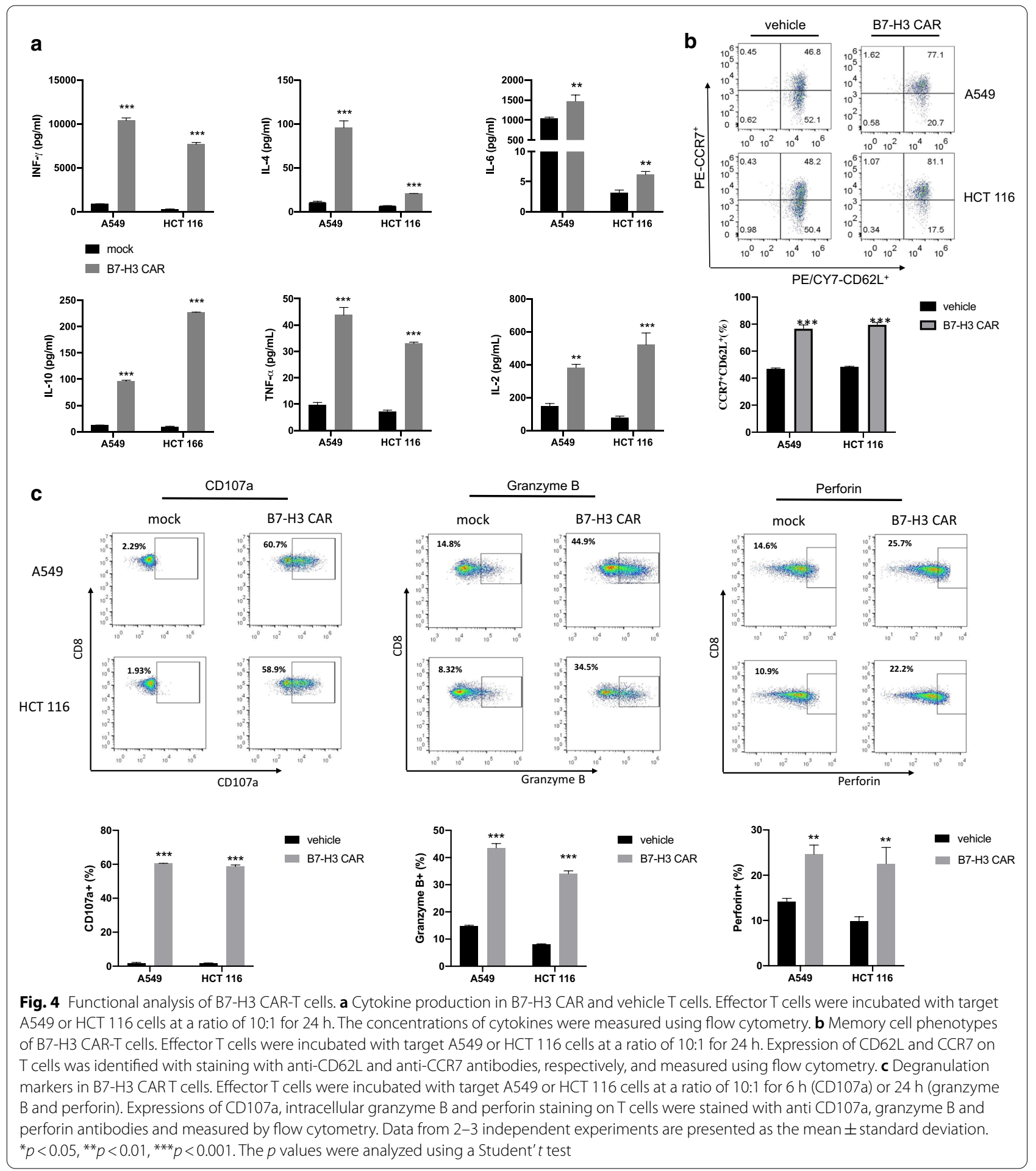

We next tested the in vivo efficacy of the BiKE in A549 and NCI-H23 xenograft NOC/SCID mice model with human PBMC infusion. Intravenous injections of the BiKE and scFvs were done twice weekly for 2 weeks. In the first experiment with A549, the BiKE was able to reduce tumor volume area under the curve (AUC) by $80 \%$ compared with that in the PBMC treated group $(p<0.001)$ (Fig. 5e). In the second experiment with $\mathrm{NCI}-\mathrm{H} 23$, the significant tumor growth repressions were observed in the BiKE group compared with PBMC 
(See figure on next page.)

Fig. 5 B7-H3/CD16 BiKE induced antitumor effect mediated by NK cells in vitro and in vivo. a Construct diagrams of B7-H3/CD16 BiKE, anti-B7-H3 scFv, and anti-CD16 scFv. b Purity of B7-H3/CD16 BiKE determined by size-exclusion chromatography. c Cytotoxicity of B7-H3/CD16 BiKE (red line), anti-B7-H3 scFv (blue line) and anti-CD16 scFv (black line) against different tumor cell lines by PBMC as effectors. $\mathbf{d}$ Comparison of ADCC induced by B7-H3/CD16 BiKE and anti-B7-H3 lgG 8H9. PBMCs were used as effectors and A549 cells were used as targets. Representative graphs are shown. For the experiments $\mathbf{c}-\mathbf{d}$, the $p$ values of the difference between BiKE and control groups were analyzed using ANOVA. $\mathbf{e}-\mathbf{h}$ Therapeutic effects of B7-H3/CD16 BiKE in A549 and NCI-H23 xenografted mice. Antibodies were administered (100 $\mu \mathrm{g}$ per dose) intravenously twice a week for a total of four doses. Human PBMCs (10 million per iv injection) were delivered intravenously twice. Tumor growth in A549-injected mice e or HCT 116-injected mice $\mathbf{g}$ was measured using digital caliper, and tumor area was calculated $(n=5)$. Mean values per treatment group are shown. Survival curves of A549-injected mice $\mathbf{f}$ or HCT 116-injected mice (h) are shown. The $p$ values of treatment were analyzed using ANOVA. The $p$ values of survival curves were analyzed using the log-rank (Mantel-Cox) test.

$(p<0.001)$ and anti-B7-H3 scFv $(p<0.05)$ (Fig. 5g), respectively. Tumor volume AUC was reduced under the curve by $75 \%$. Significantly prolonged survival was observed in the BiKE-treated groups compared with that in the group of anti-B7-H3 scFv in two experiments (Fig. 5f, h). No significant weight loss was observed in mice treated with antibodies throughout the course of this study (Additional file 1: Fig. S6C). H\&E staining showed that no evident lesions were formed in major organs collected from mice that were treated with the BiKE (Additional file 1: Fig. S11A). The serum levels of hepatic enzymes, alanine transaminase (ALT) and aspartate transaminase (AST), were measured. The activities of these enzymes are usually elevated during damage to liver cells and tissues. No significant difference was observed between the treatment and PBS-treatment groups (Additional file 1: Fig. S11B). The results suggested that the BiKE had no obvious systemic acute toxicity in major organs.

NK cell as the innate effector cell induces apoptotic cell death. To quantify BiKE-mediated tumor apoptosis induced by NK cells, we employed one a FRET-based quantitative live-cell imaging system. A549 cells expressing a caspase-3 biosensor FRET reporter (A549-C3), which indicates live cells with green fluorescence light and apoptotic cells with blue fluorescence light, were loaded with BiKE and human NK cells in the range of 12-36 h. The representative images of fluorescence of and apoptosis percentages in tumor cells are shown in Fig. 6a, b. At different time points, the BiKE induced cell apoptosis in target tumor cells mediated by NK cells, ranging from 23 to $35 \%$ of the total target cell population with statistically significant differences. Therefore, the results suggested that the recruitment of NK cells with BiKE enhanced apoptosis in target tumor cells.

B7-H3 blockade altered glucose metabolism in cancer cells Warburg effect is one feature of metabolic dysregulation during malignant transformation. To investigate the effect of anti-B7-H3 blockade in the regulation of glucose metabolism in cancer cells, we measured dynamic ECAR and OCR as indicatives of glycolysis and oxidative respiration in A549 cells. The parameters of mitochondrial respiration and glycolytic capacity of cancer cells were determined using the Mito Cell Stress and the Glycolysis Stress assays, respectively. We found that anti-B7-H3 blockade decreased basal ECAR (Fig. 7a, e) and increased basal OCR (Fig. 7b, f). ECAR was low while OCR was high, reflecting indicatives of anti-Warburg effect. ECAR was increased, reflecting the inhibition for nonglycolytic acidification and glycolytic reserve capacity (Fig. 7c), and OCR was decreased, reflecting the inhibition a greater requirement of nonmitochondrial oxygen consumption, basal respiration and ATP production oxidative phosphorylation (Fig. 7d). The cells produced ATP primarily by oxidative phosphorylation. The results suggest that antiB7-H3 blockade switches cell metabolism from glycolysis to oxidative phosphorylation. Because ROS plays essential roles in modulating glucose metabolism, we further determined whether ROS levels could be altered by antiB7-H3 blockade in A549 cells. The cellular ROS levels in A549 cells under anti-B7-H3 antibody treatment were measured by staining with fluorescent probes. We found that the treatment with anti-B7-H3 antibody resulted in lower levels of ROS (Fig. 7G and Additional file 1: Fig. S12). Thus, anti-B7-H3 blockade probably regulates glucose metabolism through cellular ROS signals.

\section{Discussion}

Despite great progress in the development of immune checkpoint inhibitors, particularly the encouraging therapy of PD-L1/PD-1 blockade, a portion of NSCLC patients remain generally resistant to these therapies [42]. There is an ongoing research aimed to discover novel immune checkpoint biomarkers and develop novel immunotherapy approaches. Overexpression of B7-H3 in tumors and its low levels in normal tissues have been described $[14,43]$. Recent studies have demonstrated that $\mathrm{B} 7-\mathrm{H} 3$ overexpression was associated with poor prognosis in NSCLC patients [16, 17]. Consistently, this study showed that B7-H3 overexpression was significantly associated with 5yr-OS of NSCLC patients. We demonstrated that $\mathrm{B} 7-\mathrm{H} 3$ was tightly expressed in human NSCLC. The expression of B7-H3 in tumor and normal tissues was analyzed based on the 


\section{a}

BiKE

\begin{tabular}{|l|l|l|l|l|l|l|}
\hline $\mathrm{VH}$ & $\left(\mathrm{G}_{S} \mathrm{~S}_{3}\right.$ & $\mathrm{VL}$ & $\left(\mathrm{G}_{4} \mathrm{~S}_{3}\right.$ & $\mathrm{VH}$ & $\left(\mathrm{G}_{3} \mathrm{~S}_{\mathrm{H}}\right.$ & $\mathrm{VL}$ \\
\hline
\end{tabular}

Anti-B7-H3 scFv

\begin{tabular}{|l|l|l|}
\hline $\mathrm{VH}$ & $\left(\mathrm{G}_{4} \mathrm{~S}_{3}\right.$ & $\mathrm{VL}$ \\
\hline
\end{tabular}

Anti-CD16 scFv
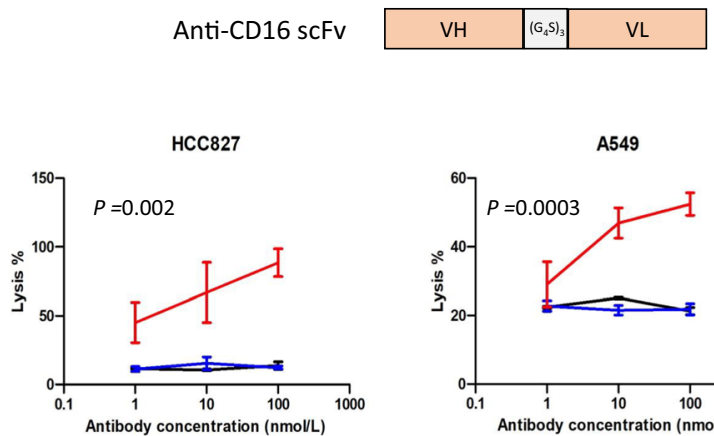

NCI-H23

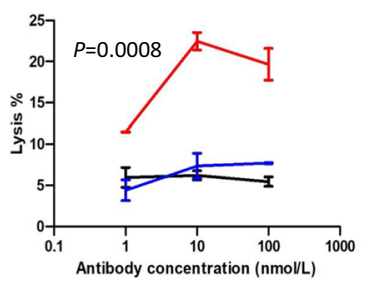

d
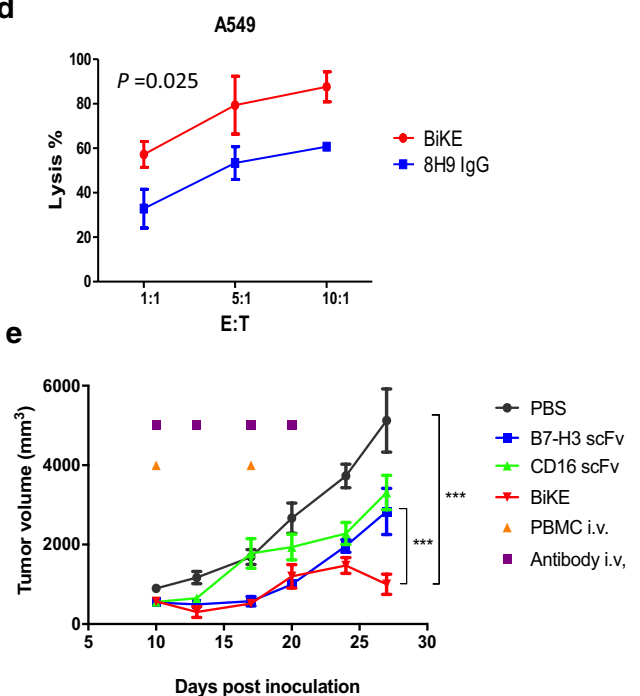

g

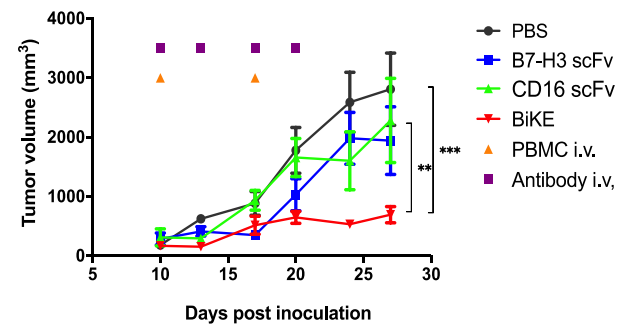

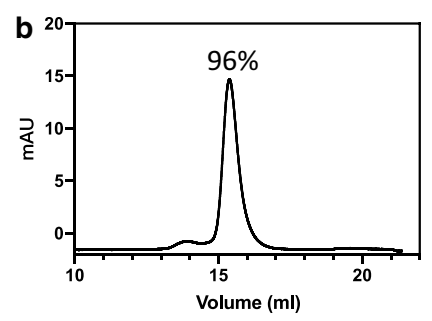

A549

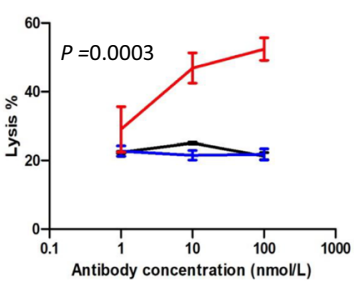

OCI-AML-3

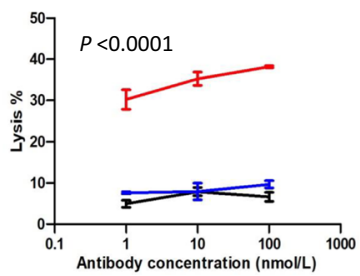

HCT 116
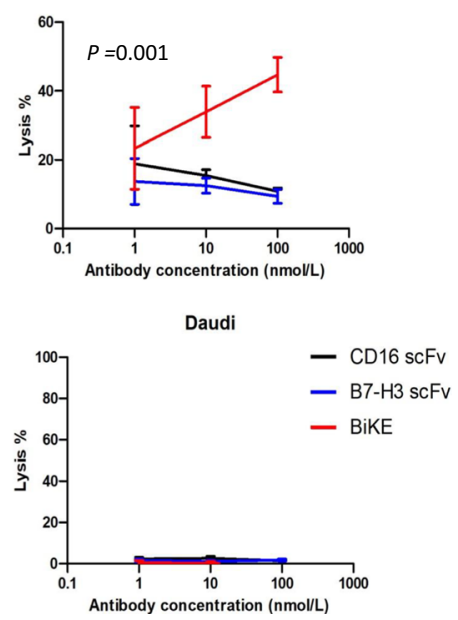
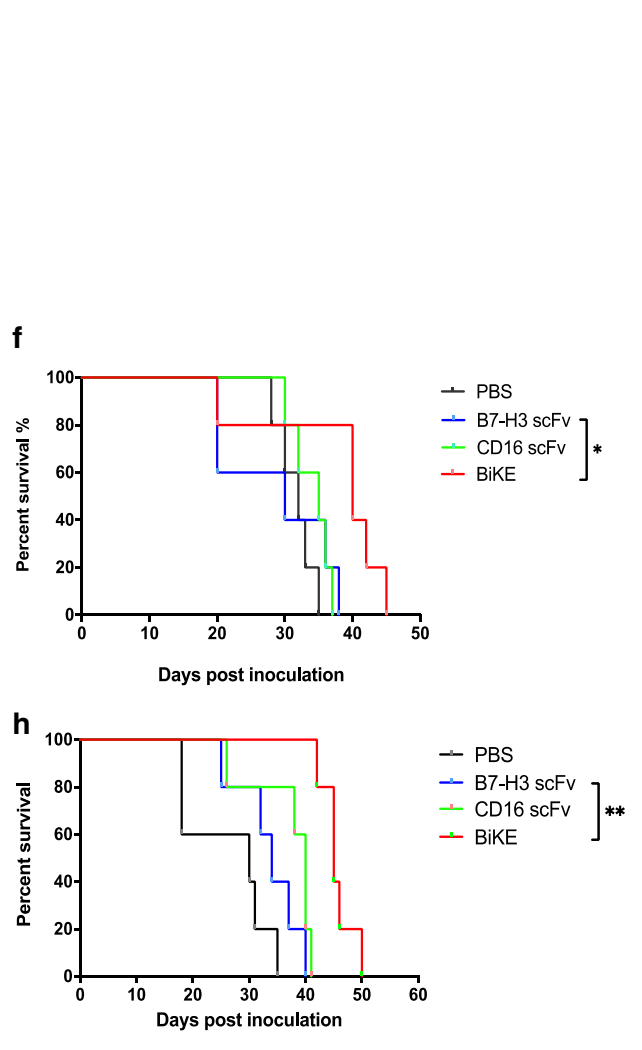

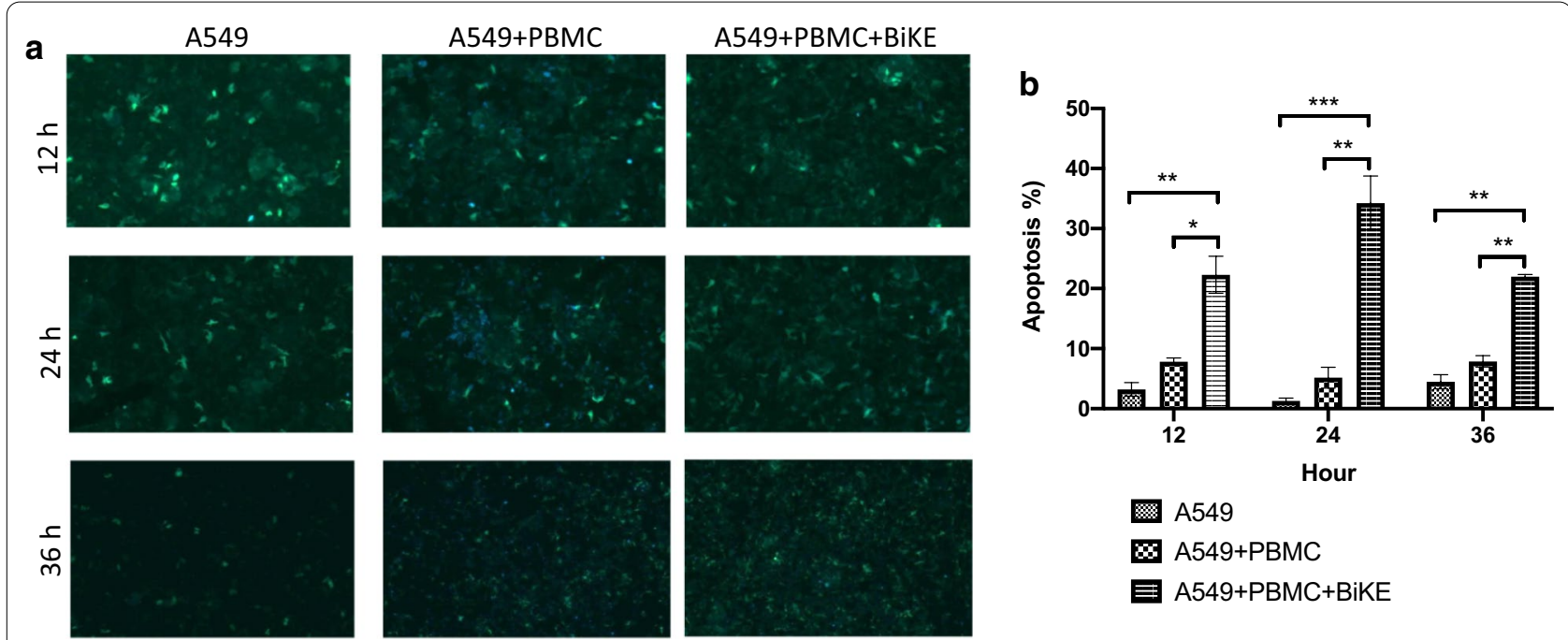

Fig. 6 Dynamic caspase-3 activation in apoptotic cells in response to B7-H3/CD16 BiKE. a FRET imaging of A549-C3 cells live cells appeared in

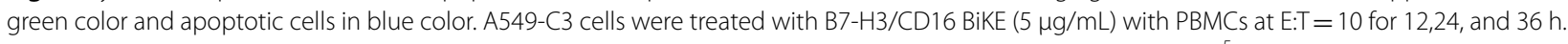
b Statistical analysis of apoptotic rate at different time points. Representative images are shown. Sample size: $1 \times 10^{5}$ target cells. The $p$ values were analyzed using a Student' $t$ test

\footnotetext{
(See figure on next page.)
}

Fig. 7 Anti-B7-H3 blockade influences on glucose metabolism and intracellular ROS in A549 tumor cells. a-f Extracellular acidification rate and oxygen consumption rate measurements using the seahorse extracellular flux analyzer. After A549 cells were treated with either anti-B7-H3 or control antibodies for $24 \mathrm{~h}$, ECAR and OCAR were examined using the Mito Stress Cell and Glycolysis Stress assays. ECAR (a, e) and OCR (b, f) metabolic profiles are shown. c Nonglycolytic acidification and glycolytic capacity were derived from Glycolysis Stress assay results. d Nonmitochondrial respiration, ATP production and basal respiration were derived from Mito Stress Cell results. $\mathbf{g}$ Intracellular ROS measurement in tumor cells. A549 cells were labeled with 2,7-dichlorofluorescin diacetate as a probe and treated with either anti-B7-H3 or control antibodies. Intracellular ROS signals were measured using flow cytometry. Data from two independent experiments are presented as the mean \pm standard deviation. $\left.{ }^{*} p<0.05,{ }^{* *} p<0.01,{ }^{* * *} p<0.001\right)$. The $p$ values were analyzed using a Student't test

data from the TCGA and IHC. According to the TCGA data, the mRNA expression levels of B7-H3 were highly associated with the malignancy grade of NSCLC. The IHC results further showed that $76 \%$ of NSCLC tissues were positive for B7-H3, which was consistent with the previous studies [18]. B7-H3 expression may be correlated with tumor metastasis, because moderate expression of B7-H3 was also observed in paracancerous tissues, although the intensity was weaker than that in tumor tissues. Thus, this finding has further confirmed utility of B7-H3 as an oncoimmunology target.

Although the regulatory mechanisms of $\mathrm{B} 7-\mathrm{H} 3$ have not been completely elucidated, B7-H3 function closely correlates with that of a cytotoxic lymphocyte. As described in previous studies, anti-B7-H3 antibody blockade augmented antitumor immunity of $\mathrm{CD} 8^{+} \mathrm{T}$ cells and NK cells $[12,18]$. The anti-B7-H3 mAb 8H9 (omburtamab) has showed clinical potential in promoting Fc-dependent NK cell through ADCC [26]. NK cells are the key component in ADCC and play a role in immunosurveillance and the prevention of tumor metastasis $[44,45]$. Unlike T cell, NK cells are devoid of receptors for tumor-associated antigens. Solid tumors are relatively resistant to NK cytotoxicity due to lack of NK activation ligands [46]. Tumor metastasis is often associated with a low NK cell activity $[47,48]$. NK dysfunctions promote metastasis in several human malignancies $[49,50]$. In this study, to overcome resistance, we examined the ability of the B7-H3/CD16 BiKE to redirect NK cells to destroy tumor cells. In fact, BiKE triggers activation of resting NK cells through CD16a signaling and thereby induces the secretion of cytokines and degranulation against B7-H3-positive tumor cells. Importantly, due to the direct binding of antibody to CD16a, NK cell cytotoxicity induced by the BiKE was superior to the Fc-mediated ADCC of anti-B7-H3 8H9 IgG. In two xenografts involving A549 (high level of B7-H3) and NCI-H23 (low level of B7-H3), our results showed that BiKE was effective to suppress NSCLC growth in both models as was demonstrated with reduced tumor volume 

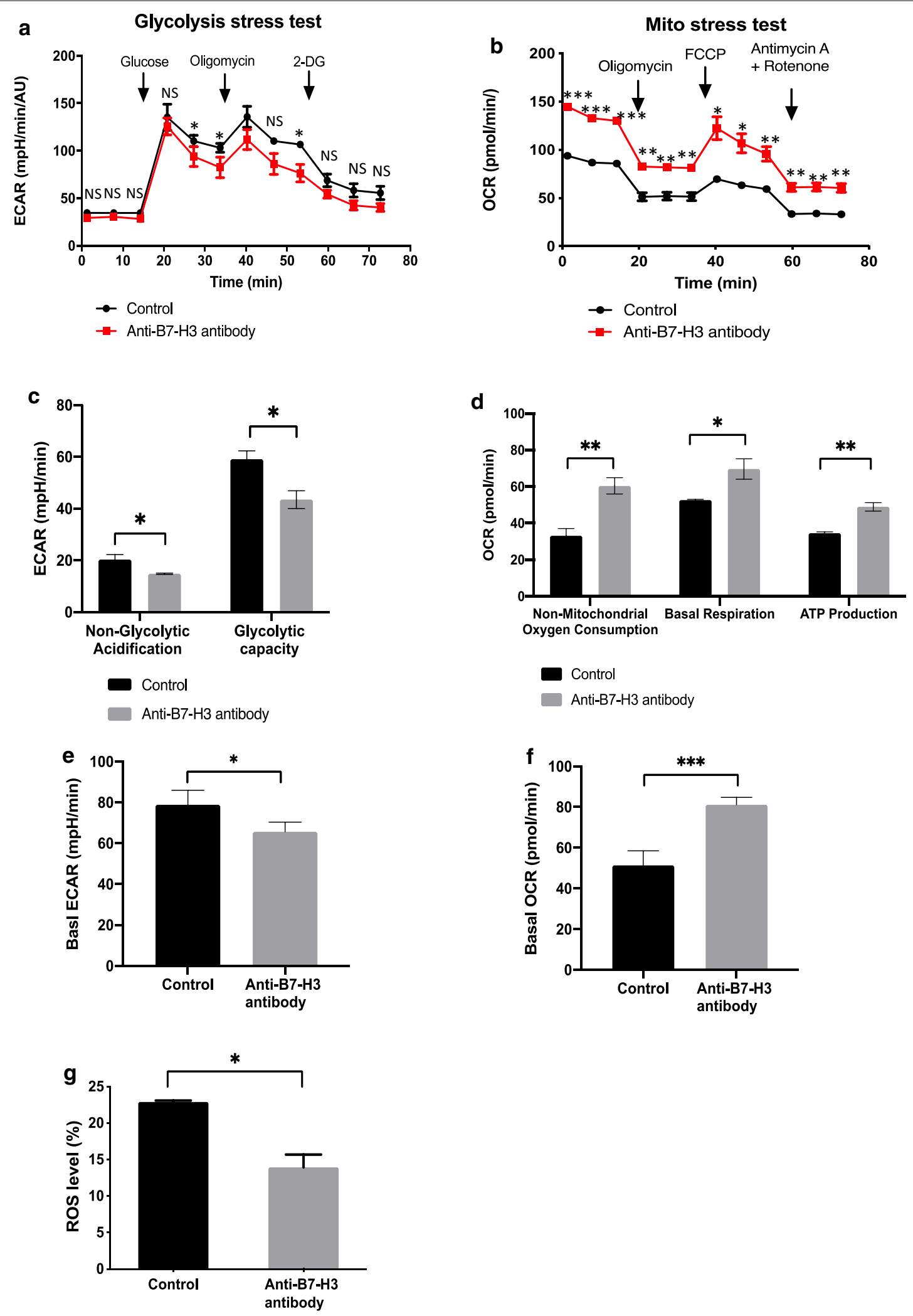

Control

Anti-B7-H3 antibody 
(75-80\%), The in vivo activity of BiKE was not limited by B7-H3 antigen density of NCI-H23 at the low level. We assume that a threshold of $\mathrm{B} 7-\mathrm{H} 3$ density is required to induce NK activity. The NK cell effector mechanisms involve caspase-dependent apoptosis [51]. Dynamics of tumor cell death induced by NK cells was observed using FRET-based quantitative live cell imaging system in which activation of caspase- 3 was used as indication of apoptosis. As NK stimulation by BiKE leads to significant increases in apoptotic target cell death, this further confirmed the ability of BiKE to actively propagate signals for NK cell activation.

In order to exploit the potential of $8 \mathrm{H} 9$ as $\mathrm{CAR}$, we described the effects of the B7-H3 CAR-based 8H9 in cytotoxicity, cytokine production and inhibition of tumor growth. Our results demonstrated that key cytokine levels and $\mathrm{T}$ cell degranulation were enhanced. B7-H3 blockade promoted $\mathrm{T}$ cells differentiation into the naïve and central memory $\mathrm{T}$ cells, reflecting the increase of $\mathrm{T}$ cell persistence. Indeed, the $\mathrm{B} 7-\mathrm{H} 3 \mathrm{CAR}$ of $8 \mathrm{H} 9$ showed significant antitumor activity in xenografts of NSCLC and colon cancer cells. The on-target off-tumor toxicity is a major safety concern in CAR-T therapy [52]. Efforts have been made to limit the toxicity, including infusing low dose of CAR-T cells [53] and optimizing antibody affinity for the target [54]. Our results showed that the B7-H3 CARs are expected to have minimal off-target toxicity. Because B7-H3 expression is limited in normal tissues, B7-H3 CAR T cells mainly extravasated into solid tumors but not into normal tissues. Consistent with this observation, we did not find evidence of damage in normal tissues. It suggests that tumor regional infiltration of B7-H3 CAR-T cells may limit systemic toxicity by reducing the cross-reactivity of CAR-T cells in other organs.

Combination strategies of immune checkpoint inhibitors provide significant benefit to some cancer patients $[55,56]$. In NSCLC patients, B7-H3 was associated with adaptive resistance to anti-PD-1 therapy [18]. An antiB7-H3 mAb, MGA271, has been assessed in a Phase I trial (NCT02475213) in combination with anti-PD-1 antibodies (pembrolizumab) in patients with melanoma. Combining blockades of $\mathrm{B} 7-\mathrm{H} 3$ and $\mathrm{PD}-1 / \mathrm{PD}-\mathrm{L} 1$ resulted in the strength of therapeutic effects mediated by CD $8+T$ cells in the mouse ovarian cancer and pancreatic cancer models $[12,18,57]$. In this study, IHC staining showed that approximately $30 \%$ of patients with NSCLC had coexpression of B7-H3 and PD-L1. On the other hand, a recent study demonstrated that PD-L1 expression by $\mathrm{T}$ cells weakened antitumor immunity through suppressing effector $\mathrm{T}$ cells and macrophages in tumor microenvironment [58]. In our studies, PD-L1 expression was found in B7-H3 CAR-T cells irrespective of PD-L1 expression in tumor cells (Additional file 1: Fig. S13). We speculate that T-cell-expressed PD-L1 is involved in modulation of B7-H3 CAR-T cells. In the preliminary experiments, one anti-PD-L1 antibody improved cytotoxicity of B7-H3 CAR T cells at the high E:T ratio of 40:1 (Additional file 1: Fig. S14), suggesting anti-PD-L1 blockade should be able to prevent the immune-suppressive signaling of PD-L1 expressed by either tumor cells or T cells. In other experiments, we observed the increased productions of IL-2 and TNF- $\alpha$ by CAR T cells that were treated with antiPD-L1 antibody (unpublished data). However, the role of PD-L1 has not yet been defined for B7-H3 CAR T cells. Future studies are needed to determine whether there is a correlation between $\mathrm{T}$ cell-associated PD-L1 and antitumor effects of B7-H3 CAR T cells in vivo. Unlike in T cells, PD-1 is not highly expressed in NK cells [59]. In contrast, BiKE effectively controlled tumor growth by modulating NK cells probably due to the limited PD-1 levels. Therefore, it may be interesting to investigate further the therapeutic efficacies of dual blockade of B7-H3 and PD-L1 in NSCLC.

Elicitation of cellular mechanism behind the antiB7-H3 blockade is important to reveal the immuneindependent functions of $\mathrm{B} 7-\mathrm{H} 3$. The Warburg effect is a metabolic hallmark of tumor cells [60]. Although recent studies suggested that $\mathrm{B} 7-\mathrm{H} 3$ modulated glucose metabolism in breast cancer and colorectal cancer [61], the effects of $\mathrm{B} 7-\mathrm{H} 3$ on aerobic glycolysis in NSCLC remain unknown. Unlike other anti-B7-H3 antibodies, $8 \mathrm{H} 9$ can recognize the FG loop of B7-H3 [26], which may be related to the regulatory functions of $\mathrm{B} 7-\mathrm{H} 3$. Here, we demonstrated that anti-B7-H3 blockade by $8 \mathrm{H} 9$ antibody switched cell metabolism from glycolysis to oxidative phosphorylation. The alteration of glucose metabolism probably was associated with cellular ROS-mediated pathway, consistent with the previous reports [61]. These results clearly showed that, in addition to immune-regulatory function, $\mathrm{B} 7-\mathrm{H} 3$ possessed immune-independent functions in NSCLC.

In summary, our study shows that B7-H3 is an attractive target in NSCLC since it is highly expressed in 76\% of the tumor specimens. Recent advances and positive clinical results from bispecific antibodies and CAR $T$ cells have shown hope and excitement. Two treatment modalities, namely the B7-H3 CAR and BiKE derived from the anti-B7-H3 mAb $8 \mathrm{H} 9$, provided an effectively control of the tumor growth in NSCLC through promoting immune cell response. Safety and immunotoxicity are considered for these immunomodulatory therapeutics. Although CAR T-cell therapy has demonstrated significant antitumor activity, it can be frequently associated with cytokine release syndrome (CRS). A significant advantage of BiKE is to present low risks of systemic toxicity [62]. In addition, another 
consideration is off-target toxicity that can cause dangerous side effects and is a major cause of clinical trial failure. Therefore, further research should explore the potential of anti-B7-H3 CAR and BiKE against NSCLC in the future preclinical and clinical studies.

\section{Supplementary Information}

The online version contains supplementary material available at https://doi. org/10.1186/s13045-020-01024-8.

Additional file 1. Supplementary method, figure and table.

\section{Abbreviations}

ADCC: Antibody-dependent cell-mediated cytotoxicity; AUC: Area under the curve; NSCLC: Non-small cell lung cancer; CAR: Chimeric antigen receptor; BiKE: Bispecific killer cell engager; NK: Natural killer; PD-1: Programmed cell death protein 1; TCGA: The Cancer Genome Atlas; LUAD: Lung adenocarcinoma; LUSC: Lung squamous cell carcinoma; FFPE: Formalin-fixed paraffin-embedded; 5yr-OS: 5-Year overall survival; scFv: Single chain variable fragment; $\mathrm{VH}$ : Heavy chain variable region; $\mathrm{VL}$ : Light chain variable region; $\mathrm{MOI}$ Multiplicity of infection; MFI: Mean fluorescence intensity; FRET: Fluorescence resonance energy transfer; IHC: Immunohistochemistry; ECAR: Extracellular acidification rate; OCR: Oxygen consumption rate; 2-DG: 2-deoxy-D-glucose; ROS: Reactive oxygen species; ALT: Alanine transaminase; AST: Aspartate transaminase; CRS: Cytokine release syndrome.

\section{Acknowledgements}

We thank the assistance of the Animal Research Core, Metabolomics Core, Histopathology Core, Bioimaging \& Stem Cell Core Facilities of FHS, University of Macau and Macau Blood Center. We thank the comments from Dr. NaiKong V. Cheung (MSKCC). We thank Prof. Gang Li and Prof. Hang Fai Kwok for the cell lines.

\section{Authors' contributions}

J.L. executed experiments of CART. S.Y. executed experiments of BiKE. B.C. and K. Z. contributed IHC of normal and NSCLC tissues. G.Z, F.Z. and L.Z. contributed B7-H3 production. Y.W, and L.D executed RNA-seq analysis. Y.M., C.H., H.L., X.L. contributed part of human tumor tissues. R.W. and G.C. contributed part of cell culture. KQ.L. contributed FRET experiments. Q.Z. supervised all aspects of the investigation and wrote the manuscript.

\section{Funding}

The authors would like to thank the support from the National Key R\&D Program of China (2019YFA0904400), the Science and Technology Development Fund, Macau SAR (File no. FDCT/131/2016/A3, FDCT/0015/2018/A1), the Guangzhou Science and Technology Program (201807010004), and the intramural research program of FHS, University of Macau (File Nos. MYRG201900069-FHS and SRG2016-00082-FHS).

\section{Availability of data and materials}

All relevant data are within the paper and its Supplementary files.

\section{Ethics approval and consent to participate}

The procedures involving human samples were approved by the Ethics Committee of the Second Affiliated Hospital, Guangzhou Medical University, and Zhuhai People's Hospital, Jinan University. All animal procedures were carried out in accordance with the ethical approval of the Animal Ethical Committee of the University of Macau.

\section{Consent for publication}

Not applicable.

\section{Competing interests}

The authors declare that they have no conflicts of interest.

\section{Author details}

${ }^{1}$ Cancer Centre, Faculty of Health Sciences, University of Macau, Taipa, Macau SPR, China. ${ }^{2}$ Institute of Translational Medicine, Faculty of Health Sciences, University of Macau, Taipa, Macau SPR, China. ${ }^{3}$ Department of Minimally Invasive Interventional Radiology and Department of Radiology, The Second Affiliated Hospital of Guangzhou Medical University, Guangzhou, Guangdong, China. ${ }^{4}$ Zhuhai People's Hospital Affiliated with Jinan University, Zhuhai, Guangdong, China.

Received: 14 October 2020 Accepted: 7 December 2020

Published online: 29 January 2021

\section{References}

1. Oser MG, Niederst MJ, Sequist LV, Engelman JA. Transformation from nonsmall-cell lung cancer to small-cell lung cancer: molecular drivers and cells of origin. Lancet Oncol. 2015;16:e165-72.

2. Riihimaki $M$, Hemminki $A$, Fallah $M$, Thomsen $H$, Sundquist $K$, Sundquist J, et al. Metastatic sites and survival in lung cancer. Lung Cancer. 2014;86:78-84.

3. Popper HH. Progression and metastasis of lung cancer. Cancer Metastasis Rev. 2016;35:75-91.

4. Zappa C, Mousa SA. Non-small cell lung cancer: current treatment and future advances. Transl Lung Cancer Res. 2016;5:288-300.

5. Chen R, Manochakian R, James L, Azzouqa AG, Shi H, Zhang Y, et al. Emerging therapeutic agents for advanced non-small cell lung cancer. J Hematol Oncol. 2020;13:58.

6. Marin-Acevedo JA, Dholaria B, Soyano AE, Knutson KL, Chumsri S, Lou Y. Next generation of immune checkpoint therapy in cancer: new developments and challenges. J Hematol Oncol. 2018;11:39.

7. Xia L, Liu Y, Wang Y. PD-1/PD-L1 blockade therapy in advanced nonsmall-cell lung cancer: current status and future directions. Oncologist. 2019;24:S31-41.

8. Ma W, Gilligan BM, Yuan J, Li T. Current status and perspectives in translational biomarker research for PD-1/PD-L1 immune checkpoint blockade therapy. J Hematol Oncol. 2016;9:47.

9. Kordbacheh T, Honeychurch J, Blackhall F, Faivre-Finn C, Illidge T. Radiotherapy and anti-PD-1/PD-L1 combinations in lung cancer: building better translational research platforms. Ann Oncol. 2018;29:301-10.

10. Picarda E, Ohaegbulam KC, Zang X. Molecular pathways: targeting B7-H3 (CD276) for human cancer immunotherapy. Clin Cancer Res. 2016;22:3425-31

11. Yang S, Wei W, Zhao Q. B7-H3, a checkpoint molecule, as a target for cancer immunotherapy. Int J Biol Sci. 2020;16:1767-73.

12. Lee YH, Martin-Orozco N, Zheng P, Li J, Zhang P, Tan H, et al. Inhibition of the $\mathrm{B} 7-\mathrm{H} 3$ immune checkpoint limits tumor growth by enhancing cytotoxic lymphocyte function. Cell Res. 2017;27:1034-45.

13. Kontos F, Michelakos T, Kurokawa T, Sadagopan A, Schwab JH, Ferrone CR, et al. B7-H3: an attractive target for antibody-based immunotherapy. Clin Cancer Res. 2020. https://doi.org/10.1158/1078-0432.CCR-20-2584.

14. Seaman $S$, Zhu Z, Saha S, Zhang XM, Yang MY, Hilton MB, et al. Eradication of tumors through simultaneous ablation of CD276/B7-H3-positive tumor cells and tumor vasculature. Cancer Cell. 2017;31(501-15):e8.

15. Kraan J, van den Broek P, Verhoef C, Grunhagen DJ, Taal W, Gratama JW, et al. Endothelial CD276 (B7-H3) expression is increased in human malignancies and distinguishes between normal and tumour-derived circulating endothelial cells. Br J Cancer. 2014;111:149-56.

16. Yim J, Koh J, Kim S, Song SG, Ahn HK, Kim YA, et al. Effects of B7-H3 expression on tumour-infiltrating immune cells and clinicopathological characteristics in non-small-cell lung cancer. Eur J Cancer. 2020;133:74-85.

17. Altan M, Pelekanou V, Schalper KA, Toki M, Gaule P, Syrigos K, et al. B7-H3 Expression in NSCLC and its association with B7-H4, PD-L1 and tumorinfiltrating lymphocytes. Clin Cancer Res. 2017;23:5202-9.

18. Yonesaka K, Haratani K, Takamura S, Sakai H, Kato R, Takegawa N, et al. B7-H3 negatively modulates CTL-mediated cancer immunity. Clin Cancer Res. 2018;24:2653-64.

19. Cai D, Li J, Liu D, Hong S, Qiao Q, Sun Q, et al. Tumor-expressed B7-H3 mediates the inhibition of antitumor T-cell functions in ovarian cancer insensitive to PD-1 blockade therapy. Cell Mol Immunol. 2020;17:227-36. 
20. Du H, Hirabayashi K, Ahn S, Kren NP, Montgomery SA, Wang X, et al. Antitumor responses in the absence of toxicity in solid tumors by targeting B7-H3 via chimeric antigen receptor T cells. Cancer Cell. 2019;35(221-37):e8.

21. Tang $X$, Zhao S, Zhang Y, Wang $Y$, Zhang Z, Yang $M$, et al. B7-H3 as a novel CAR-T therapeutic target for glioblastoma. Mol Ther Oncol. 2019;14:279-87.

22. Nehama D, Di lanni N, Musio S, Du H, Patane M, Pollo B, et al. B7-H3-redirected chimeric antigen receptor $\mathrm{T}$ cells target glioblastoma and neurospheres. EBioMedicine. 2019;47:33-43.

23. Majzner RG, Theruvath JL, Nellan A, Heitzeneder S, Cui Y, Mount CW, et al. CART cells targeting B7-H3, a pan-cancer antigen, demonstrate potent preclinical activity against pediatric solid tumors and brain tumors. Clin Cancer Res. 2019;25:2560-74.

24. Kramer K, Kushner BH, Modak S, Pandit-Taskar N, Smith-Jones P, Zanzonico $P$, et al. Compartmental intrathecal radioimmunotherapy: results for treatment for metastatic CNS neuroblastoma. J Neurooncol. 2010;97:409-18.

25. Zheng M, Yu L, Hu J, Zhang Z, Wang H, Lu D, et al. Efficacy of B7-H3-redirected BiTE and CAR-T immunotherapies against extranodal nasal natural killer/T Cell lymphoma. Transl Oncol. 2020;13:100770.

26. Ahmed M, Cheng M, Zhao Q, Goldgur Y, Cheal SM, Guo HF, et al. Humanized affinity-matured monoclonal antibody $8 \mathrm{H} 9 \mathrm{Has}$ potent antitumor activity and binds to FG Loop of tumor antigen B7-H3. J Biol Chem. 2015;290:30018-29.

27. Zhu L, Liu J, Zhou G, Ng HM, Ang IL, Ma G, et al. Targeting immune checkpoint B7-H3 antibody-chlorin e6 bioconjugates for spectroscopic photoacoustic imaging and photodynamic therapy. Chem Commun (Camb). 2019;55:14255-8.

28. Modak S, Kramer K, Gultekin SH, Guo HF, Cheung NK. Monoclonal antibody $8 \mathrm{H} 9$ targets a novel cell surface antigen expressed by a wide spectrum of human solid tumors. Cancer Res. 2001:61:4048-54.

29. Modak S, Guo HF, Humm JL, Smith-Jones PM, Larson SM, Cheung NK. Radioimmunotargeting of human rhabdomyosarcoma using monoclonal antibody 8H9. Cancer Biother Radiopharm. 2005;20:534-46.

30. Souweidane MM. Editorial: convection-enhanced delivery for diffuse intrinsic pontine glioma. J Neurosurg Pediatr. 2014;13:273-4.

31. Liu J, Zhou G, Zhang L, Zhao Q. Building potent chimeric antigen receptor T Cells with crispr genome editing. Front Immunol. 2019;10:456

32. Zhao Q. Novel chimeric antigen receptor T cells based on T-cell receptorlike antibodies. Blood Sci. 2019;1:144-7.

33. Liu D. CAR-T "the living drugs", immune checkpoint inhibitors, and precision medicine: a new era of cancer therapy. J Hematol Oncol. 2019;12:113.

34. Zhang Z, Jiang C, Liu Z, Yang M, Tang X, Wang Y, et al. B7-H3-targeted CAR-T cells exhibit potent antitumor effects on hematologic and solid tumors. Mol Ther Oncolytics. 2020;17:180-9.

35. Slaney CY, Wang P, Darcy PK, Kershaw MH. CARs versus BiTEs: a comparison between $\mathrm{T}$ cell-redirection strategies for cancer treatment. Cancer Discov. 2018;8:924-34

36. Yang S, Cao B, Zhou G, Zhu L, Wang L, Zhang L, et al. Targeting B7-H3 immune checkpoint with chimeric antigen receptor-engineered natural killer cells exhibits potent cytotoxicity against non-small cell lung cancer. Front Pharmacol. 2020;1 1:1089.

37. XuT, Ying $T$, Wang $L$, Zhang $X D$, Wang $Y$, Kang $L$, et al. A native-like bispecific antibody suppresses the inflammatory cytokine response by simultaneously neutralizing tumor necrosis factor-alpha and interleukin17A. Oncotarget. 2017:8:81860-72.

38. Bindea G, Mlecnik B, Tosolini M, Kirilovsky A, Waldner M, Obenauf AC, et al. Spatiotemporal dynamics of intratumoral immune cells reveal the immune landscape in human cancer. Immunity. 2013;39:782-95.

39. Zhao Q, Ahmed M, Guo HF, Cheung IY, Cheung NK. Alteration of Electrostatic surface potential enhances affinity and tumor killing properties of anti-ganglioside GD2 monoclonal antibody hu3F8. J Biol Chem 2015;290:13017-27.

40. Yu JQ, Liu XF, Chin LK, Liu AQ, Luo KQ. Study of endothelial cell apoptosis using fluorescence resonance energy transfer (FRET) biosensor cell line with hemodynamic microfluidic chip system. Lab Chip. 2013;13:2693-700.

41. Zhang GB, Zhou H, Chen YJ, Ge Y, Xie F, Shi Q, et al. Characterization and application of two novel monoclonal antibodies against 2lgB7-H3: expression analysis of $2 \operatorname{lgB} 7-\mathrm{H} 3$ on dendritic cells and tumor cells. Tissue Antigens. 2005;66:83-92.
42. Gettinger SN, Horn L, Gandhi L, Spigel DR, Antonia SJ, Rizvi NA, et al. Overall survival and long-term safety of nivolumab (Anti-programmed death 1 antibody, BMS-936558, ONO-4538) in patients with previously treated advanced non-small-cell lung cancer. J Clin Oncol. 2015;33:2004-12.

43. Dong P, Xiong Y, Yue J, Hanley SJB, Watari H. B7H3 As a promoter of metastasis and promising therapeutic target. Front Oncol. 2018;8:264

44. Krasnova Y, Putz EM, Smyth MJ, Souza-Fonseca-Guimaraes F. Bench to bedside: NK cells and control of metastasis. Clin Immunol. 2017;177:50-9.

45. Ochoa MC, Minute L, Rodriguez I, Garasa S, Perez-Ruiz E, Inoges S, et al. Antibody-dependent cell cytotoxicity: immunotherapy strategies enhancing effector NK cells. Immunol Cell Biol. 2017;95:347-55.

46. Cho D, Shook DR, Shimasaki N, Chang YH, Fujisaki H, Campana D. Cytotoxicity of activated natural killer cells against pediatric solid tumors. Clin Cancer Res. 2010;16:3901-9.

47. Langers I, Renoux VM, Thiry M, Delvenne P, Jacobs N. Natural killer cells: role in local tumor growth and metastasis. Biologics. 2012;6:73-82.

48. Imai K, Matsuyama S, Miyake S, Suga K, Nakachi K. Natural cytotoxic activity of peripheral-blood lymphocytes and cancer incidence: an 11-year follow-up study of a general population. Lancet. 2000;356:1795-9.

49. Bidwell BN, Slaney CY, Withana NP, Forster S, Cao Y, Loi S, et al. Silencing of Irf7 pathways in breast cancer cells promotes bone metastasis through immune escape. Nat Med. 2012;18:1224-31.

50. Chow MT, Sceneay J, Paget C, Wong CS, Duret H, Tschopp J, et al. NLRP3 suppresses NK cell-mediated responses to carcinogen-induced tumors and metastases. Cancer Res. 2012;72:5721-32.

51. Waldhauer I, Steinle A. NK cells and cancer immunosurveillance. Oncogene. 2008;27:5932-43.

52. Bonifant $\mathrm{CL}$, Jackson HJ, Brentjens RJ, Curran KJ. Toxicity and management in CAR T-cell therapy. Mol Ther Oncol. 2016;3:16011.

53. Ahmed N, Brawley VS, Hegde M, Robertson C, Ghazi A, Gerken C, et al. Human epidermal growth factor receptor 2 (HER2) -Specific chimeric antigen receptor-modified $T$ cells for the immunotherapy of HER2-positive sarcoma. J Clin Oncol. 2015;33:1688-96.

54. Drent E, Themeli M, Poels R, de Jong-Korlaar R, Yuan H, de Bruijn J, et al. A rational strategy for reducing on-target off-tumor effects of CD38-chimeric antigen receptors by affinity optimization. Mol Ther 2017:25:1946-58.

55. Sharma P, Allison JP. Immune checkpoint targeting in cancer therapy: toward combination strategies with curative potential. Cell. 2015;161:205-14

56. Koyama S, Akbay EA, Li YY, Herter-Sprie GS, Buczkowski KA, Richards WG, et al. Adaptive resistance to therapeutic PD-1 blockade is associated with upregulation of alternative immune checkpoints. Nat Commun. 2016;7:10501

57. Huang B, Luo L, Wang J, He B, Feng R, Xian N, et al. B7-H3 specific T cells with chimeric antigen receptor and decoy PD-1 receptors eradicate established solid human tumors in mouse models. Oncoimmunology. 2020;9:1684127.

58. Diskin B, Adam S, Cassini MF, Sanchez G, Liria M, Aykut B, et al. PD-L1 engagement on $T$ cells promotes self-tolerance and suppression of neighboring macrophages and effector T cells in cancer. Nat Immunol. 2020;21:442-54.

59. Judge SJ, Dunai C, Aguilar EG, Vick SC, Sturgill IR, Khuat LT, et al. Minimal PD-1 expression in mouse and human NK cells under diverse conditions. J Clin Invest. 2020;130:3051-68.

60. DeBerardinis RJ, Lum JJ, Hatzivassiliou G, Thompson CB. The biology of cancer: metabolic reprogramming fuels cell growth and proliferation. Cell Metab. 2008;7:11-20.

61. Lim S, Liu H, Madeira da Silva L, Arora R, Liu Z, Phillips JB, et al. Immunoregulatory protein $\mathrm{B} 7-\mathrm{H} 3$ reprograms glucose metabolism in cancer cells by ROS-mediated stabilization of HIF1alpha. Cancer Res. 2016;76:2231-42.

62. Tay SS, Carol H, Biro M. TriKEs and BiKEs join CARs on the cancer immunotherapy highway. Hum Vaccin Immunother. 2016;12:2790-6.

\section{Publisher's Note}

Springer Nature remains neutral with regard to jurisdictional claims in published maps and institutional affiliations. 